\title{
Genome-wide association and large-scale follow up identifies 16 new loci influencing lung function
}

\begin{abstract}
Pulmonary function measures reflect respiratory health and are used in the diagnosis of chronic obstructive pulmonary disease. We tested genome-wide association with forced expiratory volume in 1 second and the ratio of forced expiratory volume in 1 second to forced vital capacity in 48,201 individuals of European ancestry with follow up of the top associations in up to an additional 46,411 individuals. We identified new regions showing association (combined $P<5 \times 10^{-8}$ ) with pulmonary function in or near MFAP2, TGFB2, HDAC4, RARB, MECOM (also known as EVI1), SPATA9, ARMC2, NCR3, ZKSCAN3, CDC123, C10orf11, LRP1, CCDC38, MMP15, CFDP1 and KCNE2. Identification of these 16 new loci may provide insight into the molecular mechanisms regulating pulmonary function and into molecular targets for future therapy to alleviate reduced lung function.
\end{abstract}

Pulmonary function, reliably measurable by spirometry, is a heritable trait reflecting the physiological state of the airways and lungs ${ }^{1}$. Pulmonary function measures are important predictors of population morbidity and mortality ${ }^{2-4}$ and are used in the diagnosis of chronic obstructive pulmonary disease (COPD), which ranks among the leading causes of death in developed and developing countries ${ }^{5,6}$. A reduced ratio of forced expiratory volume in 1 second $\left(\mathrm{FEV}_{1}\right)$ to forced vital capacity (FVC) is used to define airway obstruction, and a reduced $\mathrm{FEV}_{1}$ is used to grade the severity of airway obstruction ${ }^{7}$.

Recently, two large genome-wide association studies (GWAS), each comprising discovery sets of more than 20,000 individuals of European ancestry, identified new loci for lung function ${ }^{8,9}$. Recognizing the need for larger data sets to increase the power to detect loci of individually modest effect size, we conducted a meta-analysis of 23 lung function GWAS comprising a total of 48,201 individuals of European ancestry (stage 1) and followed up potentially new loci in 17 further studies comprising up to 46,411 individuals (stage 2). We identified 16 additional new loci for lung function and provided evidence corroborating the association of loci previously associated with lung function $^{8-11}$. Our findings implicate a number of different mechanisms underlying regulation of lung function and highlight loci shared with complex traits and diseases, including height, lung cancer and myocardial infarction.

\section{RESULTS}

Genome-wide analysis (stage 1)

We undertook meta-analyses for cross-sectional lung function measures for approximately 2.5 million genotyped or imputed SNPs across 23 studies with a combined sample size of 48,201 adult individuals of European ancestry. Characteristics of the cohort participants and the genotyping are shown in Supplementary Table 1a and $\mathbf{b}$. We adjusted $\mathrm{FEV}_{1}$ and $\mathrm{FEV}_{1} / \mathrm{FVC}$ measures for ancestry principal components, age, age $^{2}$, sex and height as covariates. Our association testing of the inverse-normal-transformed residuals for $\mathrm{FEV}_{1}$ and $\mathrm{FEV}_{1} / \mathrm{FVC}$ assumed an additive genetic model and was stratified by ever-smoking versus never-smoking status. We performed the meta-analyses of the smoking strata within each study and of the study-specific results using inverse-variance weighting (and used the inverse of the standard error squared as the weight). We applied genomic control twice at the study level (to each smoking stratum separately and to the study-level pooled estimates) and also at the meta-analysis level to avoid inflation of the test statistics caused by cryptic population structure or relatedness (see Supplementary Table 1a for study-level estimates). Our application of genomic control at the three stages is likely to be overly conservative because it has recently been shown that in large meta-analyses, test statistics are expected to be elevated under polygenic inheritance even when there is no population structure ${ }^{12}$. The test statistic inflation $\left(\lambda_{\mathrm{GC}}\right)$ before applying genomic control at the meta-analysis level was 1.12 for $\mathrm{FEV}_{1}$ and 1.09 for $\mathrm{FEV}_{1} / \mathrm{FVC}$. Genomic inflation estimates increase with sample size, as has been shown for other traits ${ }^{13-15}$; the standardized estimates to a sample of 1,000 individuals $\left(\lambda_{\mathrm{GC} \_1,000}\right)$ were 1.002 for $\mathrm{FEV}_{1}$ and 1.002 for $\mathrm{FEV}_{1} / \mathrm{FVC}$. Plots of the meta-analysis $P$ values for $\mathrm{FEV}_{1}$ and $\mathrm{FEV}_{1} / \mathrm{FVC}$ against a uniform distribution of $P$ values expected under the null hypothesis showed deviations which were attenuated, but which persisted, after removal of SNPs in loci reported previously, consistent with additional loci being associated with lung function (Supplementary Fig. 1a).

\section{Follow-up analysis (stage 2)}

Twenty-nine new loci showing evidence of association with lung function $\left(P<3 \times 10^{-6}\right)$ in stage 1 were followed up in stage 2 by using in silico data from seven studies and by undertaking additional genotyping in ten studies for the ten highest ranked SNPs (Fig. 1). Full details of the SNP selection are given in the Online Methods. We performed an inverse-variance-weighting meta-analysis across stages 1 and 2 and obtained two-sided $P$ values for the pooled estimates. Sixteen new loci reached genome-wide significance $\left(P<5 \times 10^{-8}\right)$ and showed consistent direction of effects in both stages, comprising 12 new loci for $\mathrm{FEV}_{1} / \mathrm{FVC}, 3$ new loci for $\mathrm{FEV}_{1}$ and 1 new locus reaching 
Figure 1 Study design. We followed up in stage 2 a total of 34 SNPs showing new evidence of association $\left(P<3 \times 10^{-6}\right)$ with $\mathrm{FEV}_{1}$ and/or $\mathrm{FEV}_{1} / \mathrm{FVC}$ in a meta-analysis of the stage 1 studies. Studies with a combined total of 24,737 individuals undertook genotyping and association testing of the top ten SNPs. Seven studies (marked with an asterisk) with a combined total of 11,275 individuals had genome-wide association data and provided results for up to 34 SNPs. Researchers from GS: SFHS (marked with \#) undertook genotyping on a 32-SNP multiplex genotyping platform and so included the 32 top ranking SNPs (including proxies and both SNPs from regions that showed association with both $F E V_{1}$ and $\left.F E V_{1} / F V C\right)$. This assay failed for one SNP (rs3769124), which was subsequently replaced with the thirty-third SNP (rs4762767). We excluded rs2284746 because of poor clustering. Although rs3743563 was chosen as proxy for rs 12447804 , which had an effective $N<80 \%$ in the stage 1 meta-analysis, researchers from BHS2 were unable to genotype rs3743563 and so undertook genotyping for rs 12447804 instead. See Table 1 for definitions of all study abbreviations.

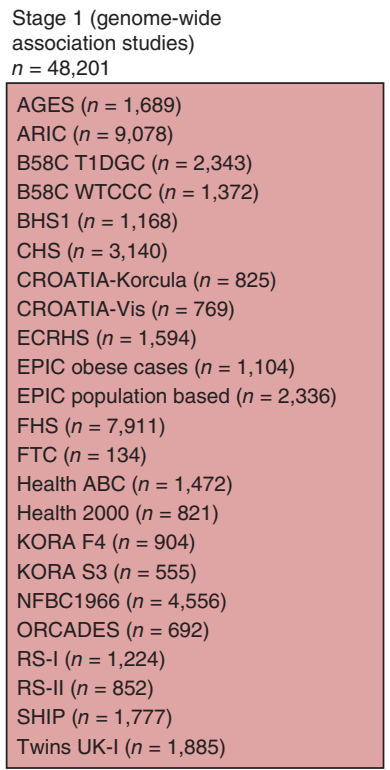

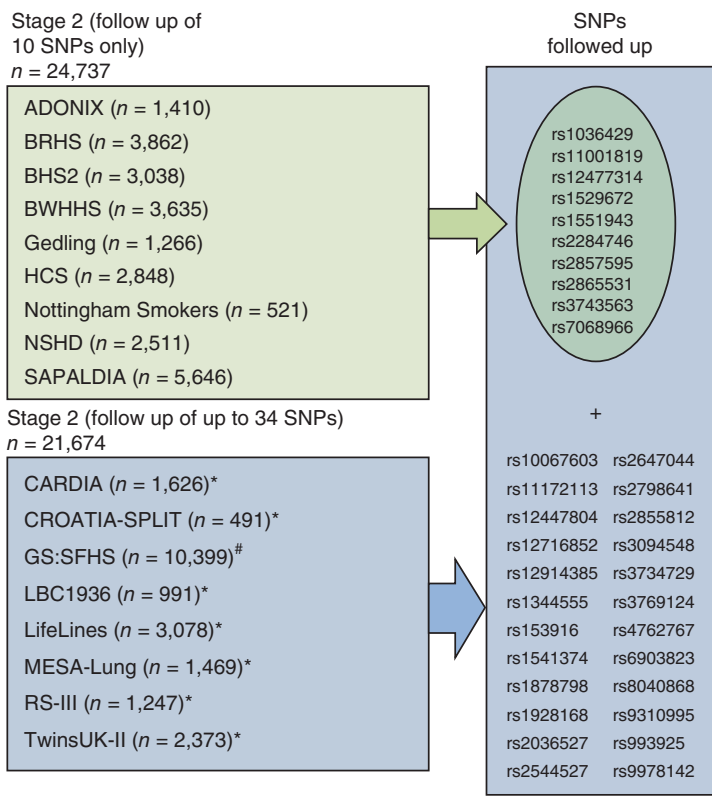

genome-wide significance for both traits (Fig. 2 and Table 1). To assess the heterogeneity across the studies included in stage 1 and 2 , we performed $\chi^{2}$ tests for all 16 SNPs, and none of these SNPs was statistically significant after applying a Bonferroni correction for 16 tests. The sentinel SNPs at these loci were in or near MFAP2 (1p36.13), TGFB2-LYPLAL1 (1q41), HDAC4-FLJ43879 (2q37.3), RARB (3p24.2), MECOM (also known as EVI1) (3q26.2), SPATA9RHOBTB3 (5q15), ARMC2 (6q21), NCR3-AIF1 (6p21.33), ZKSCAN3 (6p22.1), CDC123 (10p13), C10orf11 (10q22.3), LRP1 (12q13.3), CCDC38 (12q22), MMP15 (16q13), CFDP1 (16q23.1) and KCNE2LINC00310 (also known as C21orf82) (21q22.11) (Supplementary Fig. 1b,c). The strongest signals in AGER (rs2070600) ${ }^{8,9}$ and two of the new signals (rs6903823 in ZKSCAN3 and rs2857595, upstream of NCR3) lie within a $\sim 3.8-\mathrm{Mb}$ interval at $6 \mathrm{p} 21.32-22.1$ that is characterized by long-range linkage disequilibrium (LD). Nevertheless, the leading SNPs in these regions, which are within the major histocompatibility complex (MHC), were statistically independent (Supplementary Note).

\section{Gene expression}

We investigated mRNA expression of the nearest gene for each of the 16 new loci in human lung tissue and a range of human primary cells including lung, brain, airway smooth muscle cells and bronchial epithelial cells. We detected transcripts for all the selected genes in lung tissue except $C C D C 38$, and we also detected transcripts for most genes in airway smooth muscle cells and in bronchial epithelial cells (Table 2). As we were unable to detect expression of CCDC38 in any tissue, we also examined expression of $S N P R F$, which is the gene adjacent to CCDC38 (Table 2), and found its expression in all four cell types. TGFB2, MFAP2, EVI1 and MMP15 were expressed in one or more lung cell types but not in peripheral blood mononuclear cells, providing evidence that these genes may show tissue-specific expression.
We assessed whether SNPs in these new regions or their proxies $\left(r^{2}>0.6\right)$ were associated with gene expression using a database of expression-associated SNPs in lymphoblastoid cell lines ${ }^{16}$. Four loci showed regional (cis) effects on expression $\left(P<1 \times 10^{-7}\right.$; Supplementary Note). A proxy for our sentinel SNP in CFDP1, rs2865531, coincided with the peak of the expression signal for CFDP1, and the strongest proxy for rs6903823 in ZKSCAN3 coincided with the peak of expression for ZSCAN12.

\section{Plausible pathways for lung function involving new loci}

The putative function of the genes within, or closest to, the association peaks identify a range of plausible mechanisms for affecting lung function. The most statistically significant new signal for $\mathrm{FEV}_{1} / \mathrm{FVC}\left(P=7.5 \times 10^{-16}\right)$ was in the gene encoding MFAP2, an antigen of elastin-associated microfibrils ${ }^{17}$, although correlated SNPs in the region potentially implicate other genes that could plausibly influence lung function, such as CROCC, which encodes rootletin, a component of cilia $^{18}$. Our second strongest new signal, also for $\mathrm{FEV}_{1} / \mathrm{FVC}$, was in $R A R B$, the gene encoding the retinoic acid receptor $\beta$. Rarb-null knockout mice have premature alveolar septation ${ }^{19}$. The third most statistically significant new signal for $\mathrm{FEV}_{1} / \mathrm{FVC}$, and the most statistically significant new signal for $\mathrm{FEV}_{1}$, was in $C D C 123$.

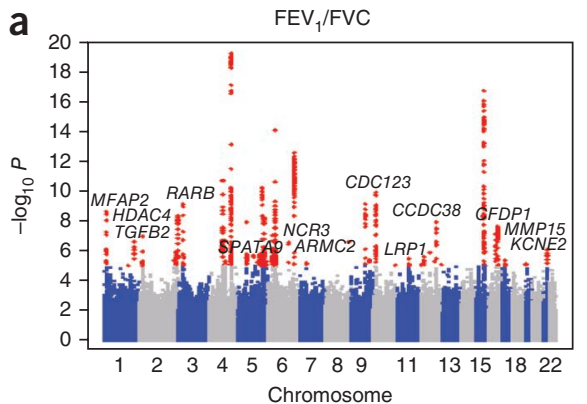

b $\quad$ FEV $_{1}$

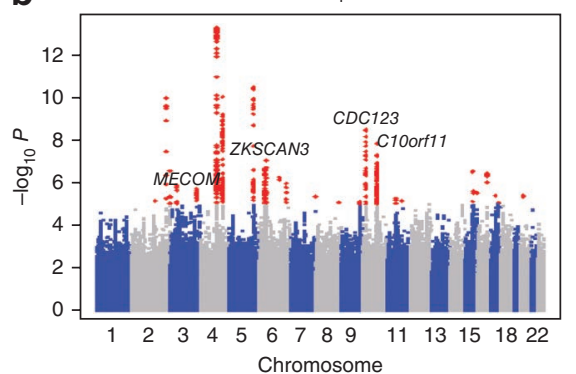

Figure 2 Manhattan plots of association results for $\mathrm{FEV}_{1} / \mathrm{FVC}$ and $\mathrm{FEV}_{1}$ (analysis stage 1 ). The Manhattan plots for $\mathrm{FEV}_{1} / \mathrm{FVC}$ (a) and $\mathrm{FEV}_{1}$ (b) are ordered by chromosome position. SNPs for which $-\log _{10} P>5$ are indicated in red. Newly associated regions that reached genome-wide significance after meta-analysis of stages 1 and 2 are labeled. 
Table 1 Loci associated with lung function

\begin{tabular}{|c|c|c|c|c|c|c|c|c|c|c|c|c|c|c|c|}
\hline \multirow[b]{2}{*}{ SNP ID } & \multirow[b]{2}{*}{ Chr. } & \multirow[b]{2}{*}{$\begin{array}{l}\text { NCBI36 } \\
\text { position }\end{array}$} & \multirow[b]{2}{*}{$\begin{array}{l}\text { Nearest } \\
\text { gene }\end{array}$} & \multirow[b]{2}{*}{$\begin{array}{c}\text { Coded } \\
\text { allele }\end{array}$} & \multirow[b]{2}{*}{ Measure } & \multicolumn{4}{|c|}{ Stage 1} & \multicolumn{3}{|c|}{ Stage 2} & \multirow[b]{2}{*}{$N$} & \multicolumn{2}{|c|}{ Joint meta-analysis of all stages } \\
\hline & & & & & & 1.) & $P$ & $\begin{array}{c}\text { Coded } \\
\text { allele } \\
\text { freq. }\end{array}$ & $N$ & 1.) & $P$ & $\begin{array}{l}\text { allele } \\
\text { freq. }\end{array}$ & & $\beta$ (s.e.m.) & $P$ \\
\hline 2284746 & 1 & $17,179,262$ & $\begin{array}{l}\text { MFAP2 } \\
\text { (intron) }\end{array}$ & G & $\begin{array}{l}\mathrm{FEV}_{1} / \mathrm{FVC} \\
\mathrm{FEV}_{1}\end{array}$ & $\begin{array}{r}-0.042(0.007) \\
0.008(0.007)\end{array}$ & $\begin{array}{l}2.47 \times 10^{-9} \\
2.78 \times 10^{-1}\end{array}$ & 0.516 & & $\begin{array}{r}-0.038(0.007) \\
0.006(0.007)\end{array}$ & $\begin{array}{l}2.64 \times 10^{-7} \\
3.70 \times 10^{-1}\end{array}$ & & & $\begin{array}{ll}1 & -0.04(0.005) \\
& 0.007(0.005)\end{array}$ & $\begin{array}{r}7.50 \times 10^{-16} \\
1.48 \times 10^{-1}\end{array}$ \\
\hline s993925 & 1 & $216,926,691$ & $\begin{array}{l}\text { TGFB2 } \\
\text { (downstream) }\end{array}$ & $\mathrm{T}$ & $\begin{array}{l}\mathrm{FEV}_{1} / \mathrm{FVC} \\
\mathrm{FEV}_{1}\end{array}$ & $\begin{array}{l}0.040(0.007) \\
0.025(0.007)\end{array}$ & $\begin{array}{l}2.54 \times 10^{-7} \\
1.51 \times 10^{-3}\end{array}$ & 0.308 & 42,402 & $\begin{array}{r}0.023(0.01) \\
0.003(0.007)\end{array}$ & $\begin{array}{l}1.76 \times 10^{-2} \\
7.29 \times 10^{-1}\end{array}$ & 0.348 & 321,414 & & $\begin{array}{l}1.16 \times 10^{-8} \\
8.71 \times 10^{-3}\end{array}$ \\
\hline rs12477314 & 42 & 239, & $\begin{array}{l}\text { HDAC4 } \\
\text { (downstream) }\end{array}$ & $\mathrm{T}$ & $\begin{array}{l}\mathrm{FEV}_{1} / \mathrm{FVC} \\
\mathrm{FEV}_{1}\end{array}$ & $\begin{array}{l}0.052(0.008) \\
0.032(0.008)\end{array}$ & $\begin{array}{l}4.48 \times 10^{-9} \\
2.77 \times 10^{-4}\end{array}$ & 0.202 & 45,585 & $\begin{array}{l}0.031(0.008) \\
0.025(0.007)\end{array}$ & $\begin{array}{l}8.41 \times 10^{-5} \\
1.82 \times 10^{-4}\end{array}$ & 0.206 & 45,821 & $\begin{array}{lll}1 & 0.041(0.006) \\
& 0.028(0.005)\end{array}$ & $\begin{array}{r}1.68 \times 10^{-12} \\
1.02 \times 10^{-7}\end{array}$ \\
\hline rs1529672 & 3 & 25,4 & $\begin{array}{l}R A R B \\
\text { (intron) }\end{array}$ & C & $\begin{array}{l}\mathrm{FEV}_{1} / \mathrm{FVC} \\
\mathrm{FEV}_{1}\end{array}$ & $\begin{array}{l}-0.060(0.009) \\
-0.037(0.009)\end{array}$ & $\begin{array}{r}7.75 \times 10^{-10} \\
1.78 \times 10^{-4}\end{array}$ & 0.829 & 40,624 & $\begin{array}{l}-0.038(0.009) \\
-0.011(0.007)\end{array}$ & $\begin{array}{l}1.16 \times 10^{-5} \\
9.33 \times 10^{-2}\end{array}$ & 0.831 & 45,466 & $\begin{array}{r}6-0.048(0.006) \\
-0.020(0.006)\end{array}$ & $\begin{array}{r}3.97 \times 10^{-14} \\
2.16 \times 10^{-4}\end{array}$ \\
\hline rs1344555 & 3 & $170,782,913$ & $\begin{array}{l}\text { MECOM } \\
\text { (intron) }\end{array}$ & $\mathrm{T}$ & $\begin{array}{l}\mathrm{FEV}_{1} / \mathrm{FVC} \\
\mathrm{FEV}_{1}\end{array}$ & $\begin{array}{l}-0.019(0.008) \\
-0.042(0.008)\end{array}$ & $\begin{array}{l}2.61 \times 10^{-2} \\
1.91 \times 10^{-6}\end{array}$ & 0.205 & 46,067 & $\begin{array}{l}-0.017(0.012) \\
-0.025(0.009)\end{array}$ & $\begin{array}{l}1.55 \times 10^{-1} \\
6.44 \times 10^{-3}\end{array}$ & 0.209 & 21,313 & $\begin{array}{r}3-0.018(0.007) \\
-0.034(0.006)\end{array}$ & $\begin{array}{l}6.65 \times 10^{-3} \\
2.65 \times 10^{-8}\end{array}$ \\
\hline rs153916 & 5 & 56 & $\begin{array}{l}\text { SPATA9 } \\
\text { (upstream) }\end{array}$ & $\mathrm{T}$ & $\begin{array}{l}\mathrm{FEV}_{1} / \mathrm{FVC} \\
\mathrm{FEV}_{1}\end{array}$ & $\begin{array}{l}-0.033(0.007) \\
-0.001(0.007)\end{array}$ & $\begin{array}{l}2.06 \times 10^{-6} \\
8.91 \times 10^{-1}\end{array}$ & 0.552 & 530 & $\begin{array}{r}-0.025(0.009) \\
0.004(0.007)\end{array}$ & $\begin{array}{l}6.67 \times 10^{-3} \\
6.22 \times 10^{-1}\end{array}$ & 0.535 & 521 & $\begin{array}{r}7-0.031(0.005) \\
0.001(0.005)\end{array}$ & $\begin{array}{l}2.12 \times 10^{-8} \\
8.20 \times 10^{-1}\end{array}$ \\
\hline s6903823 & 6 & 275 & $\begin{array}{l}3 \text { (intron)/ } \\
\text { intron) }\end{array}$ & / G & $\begin{array}{l}\mathrm{FEV}_{1} / \mathrm{FVC} \\
\mathrm{FEV}_{1}\end{array}$ & $\begin{array}{l}-0.027(0.008) \\
-0.046(0.008)\end{array}$ & $\begin{array}{l}2.28 \times 10^{-3} \\
2.00 \times 10^{-7}\end{array}$ & 0.209 & 47,057 & $\begin{array}{l}-0.013(0.011) \\
-0.029(0.008)\end{array}$ & $\begin{array}{l}2.34 \times 10^{-1} \\
4.75 \times 10^{-4}\end{array}$ & 0.246 & 21,489 & $\begin{array}{r}9-0.021(0.007) \\
-0.037(0.006)\end{array}$ & $\begin{array}{r}1.19 \times 10^{-3} \\
2.18 \times 10^{-10}\end{array}$ \\
\hline rs 285 & 6 & 48 & $\begin{array}{l}\text { NCR3 } \\
\text { (upstream) }\end{array}$ & G & $\begin{array}{l}\mathrm{FEV}_{1} / \mathrm{FVC} \\
\mathrm{FEV}_{1}\end{array}$ & $\begin{array}{l}0.049(0.009) \\
0.040(0.009)\end{array}$ & $\begin{array}{l}7.86 \times 10^{-8} \\
1.46 \times 10^{-5}\end{array}$ & 0.809 & 45 & $\begin{array}{l}0.028(0.008) \\
0.017(0.007)\end{array}$ & $\begin{array}{l}5.36 \times 10^{-4} \\
9.41 \times 10^{-3}\end{array}$ & 0.796 & 46,107 & $\begin{array}{ll}7 & 0.037(0.006) \\
& 0.025(0.005)\end{array}$ & $\begin{array}{r}2.28 \times 10^{-10} \\
1.30 \times 10^{-6}\end{array}$ \\
\hline rs2798641 & 6 & 109 & $\begin{array}{l}A R M C 2 \\
\text { (intron) }\end{array}$ & $\mathrm{T}$ & $\begin{array}{l}\mathrm{FEV}_{1} / \mathrm{FVC} \\
\mathrm{FEV}_{1}\end{array}$ & $\begin{array}{l}-0.047(0.009) \\
-0.046(0.009)\end{array}$ & $\begin{array}{l}2.81 \times 10^{-7} \\
5.39 \times 10^{-7}\end{array}$ & 0.183 & 46,369 & $\begin{array}{r}-0.030(0.012) \\
-0.009(0.01)\end{array}$ & $\begin{array}{l}1.57 \times 10^{-2} \\
3.35 \times 10^{-1}\end{array}$ & 0.179 & 21,173 & $\begin{array}{r}3-0.041(0.007) \\
-0.030(0.006)\end{array}$ & $\begin{array}{l}8.35 \times 10^{-9} \\
4.69 \times 10^{-6}\end{array}$ \\
\hline rs7068966 & 10 & 998 & $\begin{array}{l}C D C 123 \\
\text { (intron) }\end{array}$ & T & $\begin{array}{l}\mathrm{FEV}_{1} / \mathrm{FVC} \\
\mathrm{FEV}_{1}\end{array}$ & $\begin{array}{l}0.045(0.007) \\
0.040(0.007)\end{array}$ & $\begin{array}{r}1.28 \times 10^{-10} \\
1.19 \times 10^{-8}\end{array}$ & 0.519 & 47,085 & $\begin{array}{l}0.023(0.006) \\
0.022(0.005)\end{array}$ & $\begin{array}{l}3.86 \times 10^{-4} \\
3.56 \times 10^{-5}\end{array}$ & 0.518 & 46,067 & $\begin{array}{ll}7 & 0.033(0.005) \\
& 0.029(0.004)\end{array}$ & $\begin{array}{l}6.13 \times 10^{-13} \\
2.82 \times 10^{-12}\end{array}$ \\
\hline rs11001819 & 910 & 30 & $\begin{array}{l}\text { C10orf11 } \\
\text { (intron) }\end{array}$ & G & $\begin{array}{l}\mathrm{FEV}_{1} / \mathrm{FVC} \\
\mathrm{FEV}_{1}\end{array}$ & $\begin{array}{l}-0.019(0.007) \\
-0.041(0.007)\end{array}$ & $\begin{array}{l}6.50 \times 10^{-3} \\
1.42 \times 10^{-8}\end{array}$ & 0.522 & 45,546 & $\begin{array}{l}-0.006(0.006) \\
-0.022(0.005)\end{array}$ & $\begin{array}{l}3.17 \times 10^{-1} \\
3.10 \times 10^{-5}\end{array}$ & 0.506 & 45,932 & $\begin{array}{r}2-0.012(0.005) \\
-0.029(0.004)\end{array}$ & $\begin{array}{r}7.58 \times 10^{-3} \\
2.98 \times 10^{-12}\end{array}$ \\
\hline rs11172113 & 312 & $55,813,550$ & $\begin{array}{l}\angle R P 1 \\
\text { (intron) }\end{array}$ & T & $\begin{array}{l}\mathrm{FEV}_{1} / \mathrm{FVC} \\
\mathrm{FEV}_{1}\end{array}$ & $\begin{array}{l}-0.035(0.007) \\
-0.021(0.007)\end{array}$ & $\begin{array}{l}1.36 \times 10^{-6} \\
3.55 \times 10^{-3}\end{array}$ & 0.607 & 45,387 & $\begin{array}{r}-0.026(0.01) \\
-0.003(0.007)\end{array}$ & $\begin{array}{l}5.83 \times 10^{-3} \\
6.94 \times 10^{-1}\end{array}$ & 0.590 & 20,509 & $\begin{array}{r}9-0.032(0.006) \\
-0.013(0.005)\end{array}$ & $\begin{array}{l}1.24 \times 10^{-8} \\
1.19 \times 10^{-2}\end{array}$ \\
\hline rs1036429 & 12 & 59 & $\begin{array}{l}C C D C 38 \\
\text { (intron) }\end{array}$ & $\mathrm{T}$ & $\begin{array}{l}\mathrm{FEV}_{1} / \mathrm{FVC} \\
\mathrm{FEV}_{1}\end{array}$ & $\begin{array}{l}0.049(0.008) \\
0.010(0.008)\end{array}$ & $\begin{array}{l}1.24 \times 10^{-8} \\
2.67 \times 10^{-1}\end{array}$ & 0.200 & 47,814 & $\begin{array}{l}0.028(0.008) \\
0.004(0.006)\end{array}$ & $\begin{array}{l}3.35 \times 10^{-4} \\
5.38 \times 10^{-1}\end{array}$ & 0.214 & 46,311 & $\begin{array}{ll}1 & 0.038(0.006) \\
& 0.006(0.005)\end{array}$ & $\begin{array}{r}2.30 \times 10^{-11} \\
2.26 \times 10^{-1}\end{array}$ \\
\hline rs12447804 & 16 & $56,632,783$ & $\begin{array}{l}\text { MMP15 } \\
\text { (intron) }\end{array}$ & $\mathrm{T}$ & $\begin{array}{l}\mathrm{FEV}_{1} / \mathrm{FVC} \\
\mathrm{FEV}_{1}\end{array}$ & $\begin{array}{l}-0.053(0.009) \\
-0.017(0.009)\end{array}$ & $\begin{array}{l}7.12 \times 10^{-8} \\
8.02 \times 10^{-2}\end{array}$ & 0.208 & 35,123 & $\begin{array}{l}-0.021(0.01) \\
0.004(0.007)\end{array}$ & $\begin{array}{l}4.20 \times 10^{-2} \\
5.71 \times 10^{-1}\end{array}$ & 0.222 & 24,398 & $\begin{array}{r}8-0.038(0.007) \\
-0.004(0.006)\end{array}$ & $\begin{array}{l}3.59 \times 10^{-8} \\
4.73 \times 10^{-1}\end{array}$ \\
\hline rs2865531 & 16 & $73,947,817$ & $\begin{array}{l}\text { CFDP1 } \\
\text { (intron) }\end{array}$ & T & $\begin{array}{l}\mathrm{FEV}_{1} / \mathrm{FVC} \\
\mathrm{FEV}_{1}\end{array}$ & $\begin{array}{l}0.039(0.007) \\
0.024(0.007)\end{array}$ & $\begin{array}{l}2.30 \times 10^{-8} \\
6.30 \times 10^{-4}\end{array}$ & 0.418 & 47,594 & $\begin{array}{l}0.024(0.006) \\
0.011(0.005)\end{array}$ & $\begin{array}{l}1.94 \times 10^{-4} \\
3.89 \times 10^{-2}\end{array}$ & 0.409 & 46,304 & $\begin{array}{l}40.031(0.005) \\
0.016(0.004)\end{array}$ & $\begin{array}{r}1.77 \times 10^{-11} \\
1.09 \times 10^{-4}\end{array}$ \\
\hline rs9978142 & 21 & $34,574,109$ & $\begin{array}{l}\text { KCNE2 } \\
\text { (upstream) }\end{array}$ & $\mathrm{T}$ & $\begin{array}{l}\mathrm{FEV}_{1} / \mathrm{FVC} \\
\mathrm{FEV}_{1}\end{array}$ & $\begin{array}{l}-0.048(0.009) \\
-0.012(0.009)\end{array}$ & $\begin{array}{l}8.23 \times 10^{-7} \\
2.47 \times 10^{-1}\end{array}$ & 0.156 & 44,577 & $\begin{array}{r}-0.031(0.013) \\
-0.015(0.01)\end{array}$ & $\begin{array}{l}1.75 \times 10^{-2} \\
1.35 \times 10^{-1}\end{array}$ & 0.149 & 20,944 & $\begin{array}{r}4-0.043(0.008) \\
-0.013(0.007)\end{array}$ & $\begin{array}{l}2.65 \times 10^{-8} \\
5.57 \times 10^{-2}\end{array}$ \\
\hline
\end{tabular}

Shown are $\mathrm{FEV}_{1}$ and $\mathrm{FEV}_{1} / \mathrm{FVC}$ results for the leading SNPs, ordered by chromosome and position for each independent locus associated $\left(P<5 \times 10^{-8}\right)$ with $\mathrm{FEV}_{1}$ or $\mathrm{FEV}_{1} / \mathrm{FVC}$ in a joint analysis of up to 94,612 individuals of European ancestry from the SpiroMeta-CHARGE GWAS (stage 1) and follow up (stage 2). Two-sided $P$ values are given for stage 1 , stage 2 and the joint meta-analysis of all stages. $P$ values reaching genome-wide significance $\left(P<5 \times 10^{-8}\right)$ in the joint meta-analysis of all stages are indicated in bold. SNPs reaching independent replication in stage 2 $\left(P=0.05 / 34=1.47 \times 10^{-3}\right)$ are indicated with their stage $2 P$ value in bold. The sample sizes $(N)$ shown are the effective sample sizes. The effective sample size within each study is the product of sample size and the imputation quality metric. The joint meta-analysis includes data from stage 1 and stage 2 . $\beta$ values reflect effect-size estimates on an inverse-normal transformed scale after adjustments for age, age ${ }^{2}$, sex, height and ancestry principal components. The estimated proportion of the variance explained by each SNP can be found in Supplementary Table 6 . Chr., chromosome; freq., frequency.

This was the only new region to show genome-wide association with both traits. CDC123 encodes a homolog of a yeast cell-division-cycle protein that plays a critical role in modulating eukaryotic initiation factor 2 in times of cell stress ${ }^{20}$. The fourth signal for $\mathrm{FEV}_{1} / \mathrm{FVC}$ is downstream of HDAC4, which encodes a histone deacetylase; reductions in the expression of other histone deacetylases (specifically HDAC2, HDAC5 and HDAC8) have been noted in COPD ${ }^{21}$. The regions we observed in the MHC are much more difficult to localize, with multiple genes being tagged by the top SNP, including nonsynonymous SNPs in ZKSCAN3, PGBD1, ZSCAN12, ZNF323, TCF19, LTA, C6orf15 and GPANK1 (also known as BAT4) (Supplementary Table 2). At 6p21.33, we observed the strongest association with lung function for rs2857595, which is in $\operatorname{LD}\left(r^{2}=0.47\right)$ with a nonsynonymous SNP in LTA (encoding lymphotoxin $\alpha$ ) and with a SNP in the upstream promoter region of TNFA (encoding tumor necrosis factor $\alpha)\left(r^{2}=0.86\right)$, both of which are plausible candidates ${ }^{22,23}$. Our top SNP in MMP15 is in strong LD $\left(r^{2}=1\right)$ with a non-synonymous SNP (rs3743563, which has an association with $\mathrm{FEV}_{1} / \mathrm{FVC}$ at $P=1.8 \times 10^{-7}$ ) within the same gene. Among the plausible mechanisms implicated by the other new signals of association with lung function reported here is TGF- $\beta$ signaling; TGFB2 expression is upregulated in bronchial epithelial cells in asthma ${ }^{24}$. The putative function of key genes (as defined by LD with the leading SNP) in each of the 16 loci, and relevant findings from animal models, are summarized in Table 2 and are detailed in Supplementary Table 2.

\section{Associations with lung function in children}

Alleles representing 11 of the 16 new loci showed directionally consistent effects on lung function in 6,281 children (7-9 years of age) (Supplementary Table 3a), suggesting that genetic determination of lung function in adults may in part act through effects on lung development, or alternatively, that some genetic determinants of lung growth and lung function decline are shared.

\section{Association of lung function loci with other traits}

Although we stratified for ever smoking versus never smoking, we did not adjust for the amount smoked. In order to investigate the possibility that the associations at any of our 16 new regions were driven by an effect of the SNP on smoking behavior, we evaluated in silico data for associations with smoking amount from the Oxford-GlaxoSmithKline (Ox-GSK) consortium ${ }^{25}$ for the leading SNPs in these 16 regions. None of these 16 SNPs showed statistically significant association with the number of cigarettes smoked per day (Supplementary Table 3b). 
Table 2 Expression profiling of candidate genes in the lung and periphery

\begin{tabular}{|c|c|c|c|c|c|c|c|}
\hline \multirow{2}{*}{$\begin{array}{l}\text { Sentinel SNP } \\
\text { (relationship to gene) }\end{array}$} & \multirow[b]{2}{*}{ Chr. } & \multirow[b]{2}{*}{ Gene } & \multirow[b]{2}{*}{ Putative function of encoded protein } & \multicolumn{4}{|c|}{ Tissue } \\
\hline & & & & Lung & HASM & HBEC & PBMC \\
\hline rs993925 (intron) & 1 & TGFB2 & $\begin{array}{l}\text { Cytokine with roles in pro-fibrotic cytokine modulating epithelial repair mechanisms and extracellular matrix } \\
\text { homeostasis including collagen deposition }{ }^{40} \text {. }\end{array}$ & + & + & - & - \\
\hline rs2284746 (intron) & 1 & MFAP2 & $\begin{array}{l}\text { Major antigen of elastin-associated microfibrils }{ }^{17} \text { and a candidate for involvement in the etiology of inherited } \\
\text { connective tissue diseases. }\end{array}$ & + & + & + & - \\
\hline rs12477314 (downstream) & 2 & HDAC4 & $\begin{array}{l}\text { Deacetylase of histone surrounding DNA thus influencing transcription factor access to the DNA and possibly } \\
\text { repressing gene transcription. }\end{array}$ & + & + & + & + \\
\hline rs1344555 (intron) & 3 & EVI1 & Zinc finger transcription factor, encoded as part of MECOM (MDS1-EVI1 complex locus). & + & + & + & - \\
\hline rs1529672 (intron) & 3 & $R A R B$ & $\begin{array}{l}\text { Nuclear retinoic acid receptor responsive to retinoic acid, a vitamin A derivative and which also controls cell } \\
\text { proliferation and differentiation. }\end{array}$ & + & + & + & + \\
\hline rs153916 (intron) & 5 & SPATA9 & $\begin{array}{l}\text { Initially identified as a mediator of spermatogenesis, other family members may have a role in pancreatic } \\
\text { development and } \beta \text {-cell proliferation }{ }^{41} \text {. }\end{array}$ & + & + & + & + \\
\hline rs2798641 (intron) & 6 & $A R M C 2$ & $\begin{array}{l}\text { Function unknown, although other family members have been identified as having roles in cell signaling, } \\
\text { protein degradation and cytoskeleton functions }{ }^{42} \text {. }\end{array}$ & + & + & + & + \\
\hline rs2857595 (upstream) & 6 & NCR3 & Required for efficient cytotoxicity responses by natural killer cells against normal cells and tumors ${ }^{43}$. & + & - & - & + \\
\hline rs6903823 (intron) & 6 & ZKSCAN3 & Transcription factor involved in cell growth, cell cycle and signal transduction. & + & + & + & + \\
\hline rs7068966 (intron) & 10 & CDC123 & $\begin{array}{l}\text { Homolog in yeast shown to be a critical control protein modulating eukaryotic initiation factor } 2 \text { in times } \\
\text { of cell stress. }\end{array}$ & + & + & + & + \\
\hline rs11001819 (intron) & 10 & C10orf11 & Function unknown. & + & + & + & + \\
\hline rs11172113 (intron) & 12 & $L R P 1$ & Potentially diverse roles including cell signaling and migration ${ }^{44}$. & + & + & + & + \\
\hline rs1036429 (intron) & 12 & $\operatorname{CCDC38}$ & $\begin{array}{l}\text { Function unknown, although other family members involved in a diverse array of functions skeletal and } \\
\text { motor function }{ }^{45} \text {. }\end{array}$ & - & - & - & - \\
\hline $\begin{array}{l}\text { rs } 1036429\left(r^{2}=0.96\right. \\
\quad \text { with rs } 4762633 \text { in SNRPF })\end{array}$ & 12 & SNRPF & Small nuclear ribonucleoprotein $\mathrm{F}$. & + & + & + & + \\
\hline rs12447804 (intron) & 16 & MMP15 & $\begin{array}{l}\text { Member of a large protease family with diverse functional roles via protease activity and specificity including } \\
\text { tissue remodeling, wound healing, angiogenesis and tumor invasion. }\end{array}$ & + & + & + & - \\
\hline rs2865531 (intron) & 16 & CFDP1 & Craniofacial development protein 1. & + & + & + & + \\
\hline rs9978142 (upstream) & 21 & KCNE2 & KCNQ1-KCNE2 K+ channels may modulate transepithelial anion secretion in Calu3 airway epithelial cells ${ }^{46}$. & + & - & - & + \\
\hline Reference gene & 12 & GAPDH & & + & + & + & + \\
\hline
\end{tabular}

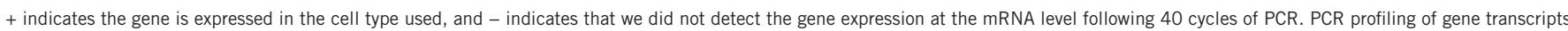
in the human lung showed expression of all candidates except $C C D C 38$, for which two sets of primers were designed and tested under different optimization conditions. None of these assays detected expression of CCDC38 in the cell types analyzed. We instead assayed SNRPF, which neighbors CCDC38 and harbors SNPs in strong LD with CCDC38's sentinel SNP. All PCR products were sequence verified. We used GAPDH (encoding glyceraldehyde-3-phosphate dehydrogenase) as a positive control for the complementary DNA, and this gene was expressed in all tissues. Chr., chromosome; HASM, human airway smooth muscle; HBEC, human bronchial epithelial cells; PBMC, peripheral blood mononuclear cells.

In addition, in our stage 1 and 2 datasets combined, we assessed whether the estimated effect sizes of the variants on lung function phenotypes differed substantially between ever smokers and never smokers (Supplementary Table 4) across the 16 loci. For the most strongly associated trait at each locus, we tested the SNP interaction with ever smoking versus never smoking. None of the 16 new loci showed a significant interaction (Bonferroni-corrected threshold for 16 independent SNPs $P=0.003125$ ). These analyses suggest that the genetic effects we have identified underlie lung function variability irrespective of smoking exposure.

We adjusted our lung function associations for height, but there are some overlaps between loci associated with height and those associated with lung function. Therefore, we evaluated in silico data for height associations of our new regions in the GIANT consortium ${ }^{14}$ dataset. The $\mathrm{G}$ allele of rs2284746 (in an intron of MFAP2), which was associated with decreased $\mathrm{FEV}_{1} / \mathrm{FVC}$, was associated with increased height (Supplementary Table 3c).

Given reported associations between lung cancer and either COPD or lung function decline, we also assessed in silico data for sentinel or proxy SNPs in these 16 regions for associations with lung cancer in the International Lung Cancer Consortium (ILCCO) GWAS meta-analysis ${ }^{26}$. Alleles associated with reduced lung function were associated with risk of lung cancer at the strongest available proxy SNP for rs 2857595 (upstream of NCR3) at 6p21.33 (rs3099844, $\left.r^{2}=0.67\right)$ and for the strongest proxy SNP for rs6903823 (a SNP in an intron of ZKSCAN3 and ZNF323) at $6 \mathrm{p} 22.1$ (rs209181, $r^{2}=0.69$ ) (lung cancer associations at $P=2.2 \times 10^{-7}$ and $P=3.4 \times 10^{-5}$, respectively; Supplementary Table $3 d$ ). We saw no significant associations with lung cancer at the other new loci (proxy SNPs were available for 15 of the 16 loci, Bonferroni-corrected $P<0.0033$ ).
In addition to the effects on height, smoking and lung cancer described above, we examined the literature for evidence of associations with other traits for each of the 16 new loci (detailed in Supplementary Table 2). Genome-wide significant associations $\left(P<5 \times 10^{-8}\right)$ have been reported in KCNE2 with myocardial infarction ${ }^{27}$ and at $6 \mathrm{p} 21.33$ near NCR3-AIF1 with neonatal lupus ${ }^{28}$ and systemic lupus erythematosus ${ }^{29}$. Other significant complex disease associations have also been noted in the regions of CDC123 (type 2 diabetes $^{30}$ ), CFDP1 (type 1 diabetes $^{31}$ ) and MECOM (blood pressure ${ }^{32,33}$ ), but with weaker LD $\left(r^{2}<0.3\right)$ being seen between the reported SNP and the sentinel SNP for lung function in the region (Supplementary Table 2).

\section{Proportion of variance explained by loci discovered to date} Associations in ten loci previously reported for lung function ${ }^{8,9}$ reached genome-wide significance $\left(P<5 \times 10^{-8}\right)$ in our stage 1 data, namely loci in or near TNS1, FAM13A, GSTCD-NPNT, HHIP, HTR4, ADAM19, AGER, GPR126, PTCH1 and TSHD4 (Supplementary Table 5a). Thus, a total of 26 regions showed genome-wide significant association with lung function in our study. In aggregate, variants at these 26 regions explain approximately $3.2 \%$ of the additive polygenic variance for $\mathrm{FEV}_{1} / \mathrm{FVC}$ and $1.5 \%$ of the variance for $\mathrm{FEV}_{1}$ (Supplementary Note). Following the approach previously described ${ }^{34}$, we estimated that there are a total of 102 (95\% confidence interval 57-155) independent variants with similar effect sizes to the 26 variants we report here. In combination, these 102 variants, comprising 26 discovered variants and 76 putative undiscovered variants, collectively explain around $7.5 \%$ of the additive polygenic variance for $\mathrm{FEV}_{1} / \mathrm{FVC}$ and $3.4 \%$ of the variance for $\mathrm{FEV}_{1}$ (Online Methods, Supplementary Table 6 and Supplementary Note). 


\section{DISCUSSION}

In meta-analysis of 23 studies comprising 48,201 individuals of European ancestry and follow up in 17 studies comprising up to 46,411 individuals, we report genome-wide significant associations with an additional 12 regions for $\mathrm{FEV}_{1} / \mathrm{FVC}$, an additional 3 regions for $\mathrm{FEV}_{1}$ and 1 additional region associated with both $\mathrm{FEV}_{1}$ and $\mathrm{FEV}_{1} / \mathrm{FVC}$. We also confirmed genome-wide association with ten regions previously associated with lung function, bringing to 26 the total number of loci associated with lung function from analyses of these datasets. Most of the new loci are in regions not previously suspected to have been involved in lung development, the control of pulmonary function or the risk of developing COPD. Elucidating the mechanisms through which these regions influence lung function should lead to a more complete understanding of lung function regulation and the pathogenesis of COPD. Four of the new loci (MFAP2, ZKSCAN3, near NCR3 and near KCNE2) that we showed to be associated with lung function are also associated with other complex traits and diseases (with $P<5 \times 10^{-8}$ for the other trait at a SNP having $r^{2}>0.3$ with the top lung function SNP in the region). Understanding the intermediates underlying these pleiotropic effects could also lead to crucial insights into the pathophysiology of lung disease. One potential explanation is that these loci underlie control of the mechanisms regulating the development and resolution of inflammation and subsequent tissue remodeling in a range of tissues.

The effect sizes of the variants in the 26 loci associated with lung function collectively explain a modest proportion of the additive genetic variance in $\mathrm{FEV}_{1} / \mathrm{FVC}$ and in $\mathrm{FEV}_{1}$, even after accounting for putative undetected variants with a similar distribution of effect sizes ${ }^{34}$. Our findings are consistent with those from other common complex traits, where it is thought that many as yet unidentified common and rare sequence variants, and potentially structural variants, could explain the remaining heritability ${ }^{35}$. That our study more than doubled the number of loci known to be associated with lung function underlines the utility of large sample sizes to achieve the power to detect common variants associated with complex traits. Nevertheless, it is likely that additional variants with similar effect sizes remain undiscovered ${ }^{14}$. In addition, our study was not designed to detect rare variants or structural variants associated with lung function. Identification of rare variants associated with lung function could be helpful in narrowing the scope of ongoing functional work to those genes most likely to be causally related to the association signals we detected.

Our study focused on cross-sectional measures of lung function. Adult lung function at a particular time point is influenced by the peak lung function achieved by $25-35$ years of age as well as the rate of decline of lung function after that peak ${ }^{36}$. The 26 loci now confirmed to be associated with lung function could affect either pre- or postnatal lung development and growth or decline in lung function during adulthood, or both. We showed consistent directions of estimated effects on lung function between adults and children 7-9 years of age for SNPs at 11 of the 16 new loci and 8 of the 10 previously reported loci (Supplementary Table 3a). The results we show for lung function in children provide some indication that these loci affect lung function development, although studies in larger populations of children would provide greater clarity for SNPs in the new loci. Further investigations will be required in large populations with longitudinal data to delineate the influence of these variants on the rates of development of, and decline in, lung function and on the risk of developing COPD.

Of the sentinel SNPs at the 16 new loci associated with lung function, only rs2284746 (MFAP2) was associated with height in the GIANT consortium ${ }^{14}$ dataset. The $\mathrm{G}$ allele of rs2284746 was associated with both increased height and reduced lung function. A similar relationship between lung function and height was previously reported for the G allele of rs3817928 in GPR126 (refs. 8,14), which is associated with decreased height but with increased $\mathrm{FEV}_{1} / \mathrm{FVC}$. A further 3 of the 180 loci found to be associated with height ${ }^{14}$ showed association (for the 180 loci, we used a Bonferroni-corrected threshold of $P=2.8 \times$ $10^{-4}$ ) with either $\mathrm{FEV}_{1}$ (CLIC4 and BMP6) or $\mathrm{FEV}_{1} / \mathrm{FVC}(P I P 4 K 2 B)$ (Supplementary Table 3e). In each case, the allele associated with an increase in height was associated with a decrease in lung function. This is not the case for the association of rs1032296 near HHIP, which has shown consistent directions of effects on lung function and height ${ }^{11,14}$ However, the strongest SNP associated with height in the HHIP region lies within an intron of HHIP but shows no association with $\mathrm{FEV}_{1}$ or $\mathrm{FEV}_{1} / \mathrm{FVC}$. Furthermore, although height is an important predictor of $\mathrm{FEV}_{1}$, this is not true for its ratio to $\mathrm{FVC}^{37}$. These observations argue against the associations with lung function at these loci being simply caused by incomplete adjustment for height.

We stratified by ever- and never-smoker status in our analyses, and in our investigation of amount smoked in the Ox-GSK consortium ${ }^{25}$, none of the sentinel SNPs in the 16 new regions showed association with the number of cigarettes smoked per day. Additionally, none of these regions was associated with ever smoking in the Ox-GSK consortium data (Supplementary Table 3b). Thus, the SNP associations with lung function we observed are unlikely to have arisen simply as a consequence of inadequate adjustment for smoking.

We did not observe any interactions with ever smoking for any of the sentinel SNPs in the 16 new regions that exceeded a Bonferronicorrected significance level (for 16 SNPs). Thus, the effects on lung function of the newly associated variants we identified are apparent in both ever smokers and in never smokers, and the effects of smoking and of these genetic variants may be independent and additive.

In other common complex diseases, follow-up studies that incorporate common genetic risk variants into models to predict disease have not been shown to add substantially to existing risk models, particularly when such models already include family history ${ }^{38,39}$. The same may also prove to be true for the 26 genetic variants described in this paper, as the effect size of any individual variant is small, but further work is required in this area. The major utility of our findings will be in the knowledge they provide about previously unknown pathways underlying lung function. Elucidating the mechanisms that these genes are involved in will lead to improved understanding of the regulation of lung function and potentially to new therapeutic targets for COPD.

URLs. R, http://www.r-project.org/.

\section{METHODS}

Methods and any associated references are available in the online version of the paper at http://www.nature.com/naturegenetics/.

Note: Supplementary information is available on the Nature Genetics website.

\section{ACKNOWLEDGMENTS}

We thank the many colleagues who contributed to collection and phenotypic characterization of the clinical sampling, genotyping and analysis of the data. We especially thank those who kindly agreed to participate in the studies.

Major funding for this work is from the following sources (alphabetical): Academy of Finland (project grants 104781, 120315, 129269, 1114194, Center of Excellence in Complex Disease Genetics (213506 and 129680) and SALVE); Althingi (Icelandic Parliament); Arthritis Research Campaign; Asthma UK; AstraZeneca; AXA Research Fund; Biotechnology and Biological Sciences Research Council (BBSRC) (BB/F019394/1, G20234); British Heart Foundation (PG/97012, PG/06/154/22043, FS05/125); British Lung Foundation; Canadian Institutes of Health Research (Grant ID MOP-82893); Cancer Research United Kingdom; 
Chief Scientist Office, Scottish Government Health Directorate (CZD/16/6); Croatian Institute for Public Health; UK Department of Health; Dutch Kidney Foundation; Erasmus Medical Center and Erasmus University, Rotterdam; Estonian Genome Center, University of Tartu, Estonia (SF0180142s08); EU funding (GABRIEL GRANT Number: 018996, ECRHS II Coordination Number: QLK4-CT-1999-01237); European Commission (DG XII, EURO-BLCS, FP-5 QLG1-CT-2000-01643, FP-6 LSHB-CT-2006-018996 (GABRIEL), FP-6 LSHG-CT2006-018947 (EUROSPAN), FP-6 GenomEUtwin project QLG2-CT-2002-01254, FP7/2007-2013: HEALTH-F2-2008-201865, GEFOS, HEALTH-F2-2008-35627, TREAT-OA, HEALTH-F4-2007-201413 (ENGAGE)); Finnish Foundation for Cardiovascular Research; Flight Attendant Medical Research Institute (FAMRI); German Asthma and COPD Network (COSYCONET: BMBF grant 01GI0883); German Bundesministerium fuer Forschung und Technology (01 AK 803 A-H, 01 IG 07015 G); German Federal Ministry of Education and Research (BMBF) (03ZIK012, 01ZZ9603, 01ZZ0103 and 01ZZ0403): German National Genome Research Network (NGFN-2 and NGFN-plus); German Ministry of Cultural Affairs; GlaxoSmithKline; Gyllenberg Foundations; Healthway, Western Australia; Helmholtz Zentrum München, German Research Center for Environmental Health, Neuherberg, Germany; Healthcare and Bioscience iNet (funded by the East Midlands Development Agency, partially financed by the European Regional Development Fund, delivered by Medilink East Midlands); Higher Education Funding Council for England (HEFCE); Hjartavernd (Icelandic Heart Association); Innsbruck Medical University; Institute for Anthropological Research in Zagreb; International Osteoporosis Foundation; Intramural Research Program of the NIH, National Institute on Aging and National Institute of Environmental Health Sciences; Jalmari and Rauha Ahokas Foundation; Juvenile Diabetes Research Foundation International (JDRF); Lifelong Health and Wellbeing Initiative (G0700704/84698); Medical Research Council UK (G1000861, G0501942, G0902313, G0000934, G0800582, G0500539, G0600705, PrevMetSyn/SALVE, G9901462); Medical Research Fund of the Tampere University Hospital; Ministry of Science, Education and Sport of the Republic of Croatia (108-1080315-0302); Medical Research Council Human Genetics Unit; Medisearch-The Leicester Medical Research Foundation; Munich Center of Health Sciences (MC Health) as part of LMUinnovativ; National Health and Medical Research Council of Australia (Grant ID 403981 and ID 003209); National Human Genome Research Institute (NHGRI) (U01-HG-004729, U01-HG-004402); National Institute for Health Research (NIHR) Comprehensive Biomedical Research Centres (Guy's \& St. Thomas' NHS Foundation Trust in partnership with King's College London and Cambridge University Hospitals NHS Foundation Trust in partnership with the University of Cambridge); Netherlands Genomics Initiative (NGI)/Netherlands Organisation for Scientific Research (NWO) (050-060-810); Netherlands Organization for the Health Research and Development (ZonMw); Netherlands Organization of Scientific Research NOW (1750102007006, 175.010.2005.011, 911-03-012); Northern Netherlands Collaboration of Provinces (SNN); Norwegian University of Science and Technology; Novo Nordisk; Ontario Institute of Cancer Research and Canadian Cancer Society Research Institute (CCSRI 020214); Republic of Croatia Ministry of Science, Education and Sports research grants (108-1080315-0302); Research Institute for Diseases in the Elderly (RIDE) (014-93-015: RIDE2); Research Into Ageing (251); Siemens Healthcare, Erlangen, Germany and the Federal State of Mecklenburg-West Pomerania; Social Ministry of the Federal State of Mecklenburg-West Pomerania; Structure Enhancing Fund (FES) of the Dutch government; Swedish Heart and Lung Foundation grant 20050561; Swedish Research Council for Worklife and Social research (FAS), grants 2001-0263, 2003-0139; Swiss National Science Foundation (grants no. 4026-28099,3347CO-108796, 3247BO-104283, 3247BO-104288, 3247BO-104284, 32-65896.01,32-59302.99, 32-52720.97, 32-4253.94); The Asthma, Allergy and Inflammation Research Trust; The Great Wine Estates of the Margaret River region of Western Australia; The Netherlands' Ministry of Economic Affairs, Ministry of Education, Culture and Science and Ministry for Health, Welfare and Sports; The Royal Society; The University of Split and Zagreb Medical Schools; Tromsø University; U01 DK062418; UBS Wealth Foundation Grant BA29s8Q7-DZZ; UK Department of Health Policy Research Programme; University Hospital Oulu, Biocenter, University of Oulu, Finland (75617); University Medical Center Groningen; University of Bristol; University of Leicester HEFCE CIF award; University of Nottingham; US National Institutes of Health (NIH) (1P50 CA70907, RO1 CA121197, U19 CA148127, CA55769, CA127219, R01HL071051, R01HL071205, R01HL071250, R01HL071251, R01HL071252, R01HL071258, R01HL071259, UL1RR025005, contracts HHSN268200625226C, HHSN268200782096C, R01-HL084099); US NIH National Cancer Institute (RO1CA111703); US NIH National Center for Research Resources (grants M01-RR00425 and 5M01 RR00997); US NIH National Eye Institute (NEI); US NIH National Heart, Lung and Blood Institute (contracts N01-HC-85079 through N01-HC-85086, N01-HC-35129, N01 HC-15103, N01 HC-55222, N01-HC-75150, N01-HC-45133, N01-HC-95095, N01-HC-48047, N01-HC-48048, N01-HC-48049,
N01-HC-48050, N01-HC-45134, N01-HC-05187, N01-HC-45205, N01-HC-45204, N01 HC-25195, N01-HC-95159 through N01-HC-95169, RR-024156, N02-HL-6-4278, R01 HL-071022, R01 HL-077612, R01 HL-074104, RC1 HL100543, HHSN268201100005C, HHSN268201100006C, HHSN268201100007C, HHSN268201100008C, HHSN268201100009C, HHSN268201100010C, HHSN268201100011C and HHSN268201100012C, grants HL080295, HL087652, HL105756, R01-HL-084099, R01HL087641, R01HL59367, R01HL086694, HL088133, HL075336 5R01HL087679-02 through the STAMPEED program (1RL1MH083268-01), 1K23HL094531-01); US NIH National Institute of Allergy and Infectious Diseases (NIAID); US NIH National Institute of Child Health and Human Development (NICHD); US NIH National Institute of Diabetes and Digestive and Kidney Diseases (NIDDK) (DK063491); US NIH National Institute of Environmental Health Sciences (NIEHS) (ZO1 ES49019, ES015794); US NIH National Institute of Mental Health (NIMH) (5R01MH63706:02); US NIH National Institute of Neurological Disorders and Stroke (NINDD); US NIH National Institute on Aging (NIA) (R01 AG032098, RC1 AG035835, N01AG12100, N01AG62101, N01AG62103, N01AG62106, 1R01AG032098-01A1, AG-023269, AG-15928, AG-20098, AG-027058); Wellcome Trust (077016/Z/05/Z, GR069224, 068545/Z/02, 076113/B/04/Z, 079895).

\section{AUTHOR CONTRIBUTIONS}

Author contributions are listed in alphabetical order. See Supplementary Note for definitions of study acronyms.

Project conception, design and management. Stage 1 GWAS, AGES: G.E., M.G., V.G., T.B.H., L.J.L. ARIC: S.J.L., N.F., L.R.L., D.J.C., D.B.H., B.R.J., A.C.M., K.E.N. B58C-T1DGC: D.P.S. B58C -WTCCC: D.P.S. BHS1: A.L.J., A.W.M., L.J.P. CHS: S.A.G., S.R.H., T.L., B.M.P. CROATIA-Korcula: H.C., I.G., S.J., I.R., A.F.W., L.Z. CROATIA-Vis: H.C., C.H., O.P., I.R., A.F.W. ECRHS: D.L.J., E.O., I.P., M.W. EPIC: N.J.W. FHS: J.B.W., G.T.O. FTC: J.K., K.H.P., T. Rantanen. Health ABC: M.C.A., P.A.C., T.B.H., S.B.K., Y.L., B.M. Health 2000: M.H., M.K. KORA F4: J. Heinrich. KORA S3: C.G., H.-E.W. NFBC1966: P.E., A.-L.H., M.-R.J., A.P. ORCADES: H.C., S.H.W., J.F.W., A.F.W. RS: A. Hofman. SHIP: S.G., G.H., B.K., H.V. TwinsUK: T.D.S., G.Z. Stage 2 follow up, ADONIX: J. Brisman., A.-C.O. BHS2: J. Beilby. BRHS: R.W.M., S.G.W., P.H.W. BWHHS: G.D.S., S.E., D.A.L., P.H.W. CARDIA: A.S. CROATIA-Split: M.B., I.K., T.Z. GS: SFHS: C.M.J., S.M.K., A.D.M., D.J.P. HCS: C.C., J.W.H., A.A.S. LBC1936: I.J.D., S.E.H., J.M.S. LifeLines: H.M.B., D.S.P., J.M.V., C.W. MESA-Lung: R.G.B., J.L.H. Nottingham smokers: I.P.H. NSHD: R.H., D.K. SAPALDIA: N.P.-H., T. Rochat. Look-up studies, ALSPAC: R.G., J. Henderson. ILCCO: ILCCO data. Ox-GSK: C.F., J.M.

Phenotype collection and data management. Stage 1 GWAS, AGES: T.A. ARIC: D.J.C., N.F., L.R.L., A.C.M., K.E.N. B58C-T1DGC: A.R.R., D.P.S. B58C - WTCCC: A.R.R., D.P.S. BHS1: A.L.J., A.W.M., L.J.P. CHS: S.A.G., S.R.H., T.L., B.M.P. CROATIA-Korcula: I.G., S.J., O.P., I.R., L.Z. CROATIA-Vis: H.C., C.H., O.P., I.R., A.F.W. ECRHS: D.L.J., E.O., I.P., M.W. EPIC: N.J.W. FHS: J.B.W., G.T.O. FTC: J.K., K.H.P., T. Rantanen. Health ABC: P.A.C., B.M., W.T. Health 2000: M.H., M.K. KORA F4: S.K., H.S. KORA S3: N.P.-H. NFBC1966: P.E., A.-L.H., M.-R.J., A.P. ORCADES: H.C., S.H.W., J.F.W. RS: G.G.B., M.E., D.W.L., B.H.Ch.S. SHIP: S.G., B.K., H.V. TwinsUK: C.J.H., P.G. Hysi, M.M., T.D.S., G.Z. Stage 2 follow up, ADONIX: J. Brisman, A.-C.O. BHS2: J. Beilby, M.L.H. BRHS: R.W.M., S.G.W., P.H.W. BWHHS: G.D.S., S.E., D.A.L., P.H.W. CARDIA: O.D.W. CROATIA-Split: M.B., I.K., T.Z. GS: SFHS: C.M.J., A.D.M. HCS: C.C., K.A.J., A.A.S. LBC1936: I.J.D., L.M.L., J.M.S. LifeLines: D.S.P., J.M.V. MESA-Lung: R.G.B., J.L.H. Nottingham smokers: K.A.A.B., J.D.B., I.P.H., A. Henry, M.O., I. Sayers. NSHD: R.H., D.K. SAPALDIA: N.P.-H. Look-up studies, ALSPAC: R.G., J. Henderson. ILCCO: ILCCO. Raine: W.Q.A., P.G. Holt, C.E.P., P.D.S.

Genotyping. Stage 1 GWAS, B58C-T1DGC: W.L.M. B58C-WTCCC: W.L.M. BHS1: A.L.J., A.W.M., L.J.P. CHS: S.R.H., B.M.P., J.I.R. CROATIA-Vis: C.H., I.R., A.F.W. ECRHS: M.W. EPIC: I.B., R.J.F.L., J.H.Z. FTC: J.K. Health ABC: Y.L., K.L. Health 2000: S.R., I. Surakka. KORA F4: N.K. KORA S3: C.G. NFBC1966: P.E., A.-L.H., M.-R.J., A.P., A.R. ORCADES: H.C., J.F.W. RS: F.R., A.G.U. SHIP: G.H. TwinsUK: C.J.H., S.-Y.S. Stage 2 follow up, ADONIX: S.D., F.N., A.-C.O. BHS2: J. Beilby, G.C., J.H. BRHS: A.D.H., R.W.M. BWHHS: S.E., D.A.L. CARDIA: M.F., X.G. CROATIASplit: V.B., T.Z. Gedling: J.R.B., T.M. GS: SFHS: C.M.J., S.M.K., D.J.P. HCS: J.W.H. LBC1936: I.J.D., S.E.H., L.M.L., J.M.S. LifeLines: C.W. MESA-Lung: S.S.R. NSHD: D.K., A.W. SAPALDIA: M.I., F.K. Look-up studies, ALSPAC: S.M.R., W.L.M. ILCCO: ILCCO. Raine: W.Q.A., C.E.P.

Data analysis. Stage 1 GWAS, AGES: G.K.G., A.V.S. ARIC: N.F., D.B.H., L.R.L. B58C-T1DGC: A.R.R., D.P.S. B58C - WTCCC: A.R.R., D.P.S. BHS1: N.M.W. CHS: K.D.M., J.I.R. CROATIA-Korcula: C.H., J.E.H., V.V. CROATIA-Vis: C.H., V.V. ECRHS: D.L.J., A.R. EPIC: J.H.Z. FHS: J.B.W. FTC: I. Surakka. Health ABC: P.A.C., Y.L., K.L., W.T. Health 2000: M.K., S.R., I. Surakka. KORA S3: E.A. NFBC1966: 
A.R. ORCADES: C.H., V.V. RS: M.E., D.W.L. SHIP: S.G., G.H., B.K., H.V. TwinsUK M.M., G.Z. Stage 2 follow-up studies, ADONIX: S.D., F.N. BHS2: G.C. BRHS: R.W.M. BWHHS: D.A.L. CARDIA: M.F., X.G. HCS: J.W.H., K.A.J. LBC1936: L.M.L. LifeLines: H.M.B. MESA-Lung: A.M., S.S.R. Nottingham smokers: I. Sayers, A. Henry. NSHD: D.G., R.H. SAPALDIA: I.C., M.I. Look-up studies, ALSPAC: D.M.E. ILCCO: ILCCO. Ox-GSK: J.Z.L. Raine: W.Q.A.

Analysis group: SpiroMeta consortium: I.P.H., T.J., M.S.A., M.D.T., L.V.W. CHARGE consortium: N.F., S.J.L., D.W.L., K.D.M., A.V.S., W.T., J.B.W.

Expression profiling and bioinformatics group: SpiroMeta consortium: I.P.H., M.O., I. Sayers, M.S.A., M.D.T., L.V.W. CHARGE consortium: S.A.G., D.W.L.

Writing group: SpiroMeta consortium: P.E., I.P.H., M.O., M.S.A., D.P.S., M.D.T., L.V.W. CHARGE consortium: S.J.L., D.W.L., S.A.G., G.T.O., V.G., B.H.Ch.S., W.T.

\section{COMPETING FINANCIAL INTERESTS}

The authors declare competing financial interests: details accompany the full-text HTML version of the paper at http://www.nature.com/naturegenetics/.

Published online at http://www.nature.com/naturegenetics/.

Reprints and permissions information is available online at http://www.nature.com/ reprints/index.html.

1. Wilk, J.B. et al. Evidence for major genes influencing pulmonary function in the NHLBI family heart study. Genet. Epidemiol. 19, 81-94 (2000).

2. Hole, D.J. et al. Impaired lung function and mortality risk in men and women: findings from the Renfrew and Paisley prospective population study. Br. Med. J. 313, 711-715, discussion 715-716 (1996).

3. Strachan, D.P. Ventilatory function, height, and mortality among lifelong nonsmokers. J. Epidemiol. Community Health 46, 66-70 (1992).

4. Young, R.P., Hopkins, R. \& Eaton, T.E. Forced expiratory volume in one second: not just a lung function test but a marker of premature death from all causes. Eur. Respir. J. 30, 616-622 (2007).

5. Lopez, A.D. et al. Chronic obstructive pulmonary disease: current burden and future projections. Eur. Respir. J. 27, 397-412 (2006).

6. Mathers, C.D. \& Loncar, D. Projections of global mortality and burden of disease from 2002 to 2030. PLoS Med. 3, e442 (2006).

7. Rabe, K.F. et al. Global strategy for the diagnosis, management, and prevention of chronic obstructive pulmonary disease: GOLD executive summary. Am. J. Respir. Crit. Care Med. 176, 532-555 (2007).

8. Hancock, D.B. et al. Meta-analyses of genome-wide association studies identify multiple loci associated with pulmonary function. Nat. Genet. 42, 45-52 (2010).

9. Repapi, E. et al. Genome-wide association study identifies five loci associated with lung function. Nat. Genet. 42, 36-44 (2010).

10. Pillai, S.G. et al. A genome-wide association study in chronic obstructive pulmonary disease (COPD): identification of two major susceptibility loci. PLoS Genet. 5, e1000421 (2009)

11. Wilk, J.B. et al. A genome-wide association study of pulmonary function measures in the Framingham Heart Study. PLoS Genet. 5, e1000429 (2009).

12. Yang, J. et al. Genomic inflation factors under polygenic inheritance. Eur. J. Hum. Genet. 19, 807-812 (2011).

13. Elks, C.E. et al. Thirty new loci for age at menarche identified by a meta-analysis of genome-wide association studies. Nat. Genet. 42, 1077-1085 (2010).

14. Lango Allen, $\mathrm{H}$. et al. Hundreds of variants clustered in genomic loci and biological pathways affect human height. Nature 467, 832-838 (2010).

15. Lindgren, C.M. et al. Genome-wide association scan meta-analysis identifies three loci influencing adiposity and fat distribution. PLoS Genet. 5, e1000508 (2009).

16. Dixon, A.L. et al. A genome-wide association study of global gene expression. Nat. Genet. 39, 1202-1207 (2007)

17. Gibson, M.A., Hughes, J.L., Fanning, J.C. \& Cleary, E.G. The major antigen of elastinassociated microfibrils is a 31-kDa glycoprotein. J. Biol. Chem. 261, 11429-11436 (1986).

18. Yang, J. et al. Rootletin, a novel coiled-coil protein, is a structural component of the ciliary rootlet. J. Cell Biol. 159, 431-440 (2002).

19. Massaro, G.D. et al. Retinoic acid receptor- $\beta$ : an endogenous inhibitor of the perinatal formation of pulmonary alveoli. Physiol. Genomics 4, 51-57 (2000).
20. Bieganowski, P., Shilinski, K., Tsichlis, P.N. \& Brenner, C. Cdc123 and checkpoint forkhead associated with RING proteins control the cell cycle by controlling elF2 $\gamma$ abundance. J. Biol. Chem. 279, 44656-44666 (2004).

21. Ito, K. et al. Decreased histone deacetylase activity in chronic obstructive pulmonary disease. N. Engl. J. Med. 352, 1967-1976 (2005).

22. Wu, $\mathrm{H}$. et al. Parental smoking modifies the relation between genetic variation in tumor necrosis factor- $\alpha$ (TNF) and childhood asthma. Environ. Health Perspect. 115 616-622 (2007).

23. Ruse, C.E. et al. Tumour necrosis factor gene complex polymorphisms in chronic obstructive pulmonary disease. Respir. Med. 101, 340-344 (2007).

24. Chu, H.W. et al. Transforming growth factor- $\beta 2$ induces bronchial epithelial mucin expression in asthma. Am. J. Pathol. 165, 1097-1106 (2004).

25. Liu, J.Z. et al. Meta-analysis and imputation refines the association of $15 \mathrm{q} 25$ with smoking quantity. Nat. Genet. 42, 436-440 (2010).

26. Landi, M.T. et al. A genome-wide association study of lung cancer identifies a region of chromosome 5p15 associated with risk for adenocarcinoma. Am. J. Hum. Genet. $\mathbf{8 5}$ 679-691 (2009)

27. Kathiresan, S. et al. Genome-wide association of early-onset myocardial infarction with single nucleotide polymorphisms and copy number variants. Nat. Genet. 41 , 334-341 (2009).

28. Clancy, R.M. et al. Identification of candidate loci at 6 p21 and 21q22 in a genome wide association study of cardiac manifestations of neonatal lupus. Arthritis Rheum. 62 3415-3424 (2010).

29. Harley, J.B. et al. Genome-wide association scan in women with systemic lupus erythematosus identifies susceptibility variants in ITGAM, PXK, KIAA1542 and othe loci. Nat. Genet. 40, 204-210 (2008).

30. Zeggini, E. et al. Meta-analysis of genome-wide association data and large-scale replication identifies additional susceptibility loci for type 2 diabetes. Nat. Genet. 40 , 638-645 (2008).

31. Barrett, J.C. et al. Genome-wide association study and meta-analysis find that over 40 loci affect risk of type 1 diabetes. Nat. Genet. 41, 703-707 (2009).

32. Levy, D. et al. Genome-wide association study of blood pressure and hypertension. Nat. Genet. 41, 677-687 (2009).

33. Newton-Cheh, C. et al. Genome-wide association study identifies eight loci associated with blood pressure. Nat. Genet. 41, 666-676 (2009).

34. Park, J.H. et al. Estimation of effect size distribution from genome-wide association studies and implications for future discoveries. Nat. Genet. 42, 570-575 (2010).

35. Yang, J. et al. Genome partitioning of genetic variation for complex traits using common SNPs. Nat. Genet. 43, 519-525 (2011).

36. Kohansal, R. et al. The natural history of chronic airflow obstruction revisited: an analysis of the framingham offspring cohort. Am. J. Respir. Crit. Care Med. 180, 3-10 (2009).

37. Hankinson, J.L., Odencrantz, J.R. \& Fedan, K.B. Spirometric reference values from a sample of the general U.S. population. Am. J. Respir. Crit. Care Med. 159, 179-187 (1999)

38. Talmud, P.J. et al. Utility of genetic and non-genetic risk factors in prediction of type 2 diabetes: Whitehall II prospective cohort study. Br. Med. J. 340, b4838 (2010).

39. Wacholder, S. et al. Performance of common genetic variants in breast-cancer risk models. N. Engl. J. Med. 362, 986-993 (2010).

40. Thompson, H.G.R., Mih, J.D., Krasieva, T.B., Tromberg, B.J. \& George, S.C. Epithelialderived TGF- $\beta 2$ modulates basal and wound-healing subepithelial matrix homeostasis. Am. J. Physiol. Lung Cell. Mol. Physiol. 291, L1277-L1285 (2006).

41. Maran, C., Tassone, E., Masola, V. \& Onisto, M. The story of SPATA2 (spermatogenesisassociated protein 2): from Sertoli cells to pancreatic $\beta$-cells. Curr. Genomics 10 , 361-363 (2009).

42. Tewari, R., Bailes, E., Bunting, K.A. \& Coates, J.C. Armadillo-repeat protein functions: questions for little creatures. Trends Cell Biol. 20, 470-481 (2010).

43. Pende, D. et al. Identification and molecular characterization of NKp30, a novel triggering receptor involved in natural cytotoxicity mediated by human natural kille cells. J. Exp. Med 190, 1505-1516 (1999).

44. Lillis, A.P., Mikhailenko, I. \& Strickland, D.K. Beyond endocytosis: LRP function in cell migration, proliferation and vascular permeability. J. Thromb. haemost. $\mathbf{3}$ 1884-1893 (2005).

45. Burkhard, P., Stetefeld, J. \& Strelkov, S.V. Coiled coils: a highly versatile protein folding motif. Trends Cell Biol. 11, 82-88 (2001).

46. Cowley, E.A. \& Linsdell, P. Characterization of basolateral $\mathrm{K}^{+}$channels underlying anion secretion in the human airway cell line Calu-3. J. Physiol. (Lond.) 538 747-757 (2002). 
María Soler Artigas ${ }^{1,2,128}$, Daan W Loth ${ }^{3,4,128}$, Louise V Wain ${ }^{1,2,128}$, Sina A Gharib ${ }^{5,6,128}$, Ma'en Obeidat $^{7,128}$, Wenbo Tang ${ }^{8,128}$, Guangju Zhai ${ }^{9,10}$, Jing Hua Zhao ${ }^{11}$, Albert Vernon Smith ${ }^{12,13}$, Jennifer E Huffman ${ }^{14}$, Eva Albrecht ${ }^{15}$, Catherine M Jackson ${ }^{16}$, David M Evans ${ }^{17}$, Gemma Cadby ${ }^{18,19}$, Myriam Fornage ${ }^{20,21}$, Ani Manichaikul ${ }^{22,23}$, Lorna M Lopez ${ }^{24,25}$, Toby Johnson ${ }^{26}$, Melinda C Aldrich ${ }^{27,28}$, Thor Aspelund ${ }^{12,13}$, Inês Barroso ${ }^{29,30}$, Harry Campbell ${ }^{31}$, Patricia A Cassano ${ }^{8}$, David J Couper ${ }^{32}$, Gudny Eiriksdottir ${ }^{12}$, Nora Franceschini ${ }^{33}$, Melissa Garcia ${ }^{34}$, Christian Gieger ${ }^{15}$, Gauti Kjartan Gislason ${ }^{12}$, Ivica Grkovic ${ }^{35}$, Christopher J Hammond ${ }^{9}$, Dana B Hancock ${ }^{36,37}$, Tamara B Harris ${ }^{34}$, Adaikalavan Ramasamy ${ }^{38-40,}$ Susan R Heckbert ${ }^{41-43}$, Markku Heliövaara ${ }^{44}$, Georg Homuth ${ }^{45}$, Pirro G Hysi ${ }^{9}$, Alan L James ${ }^{46-48}$, Stipan Jankovic ${ }^{35}$, Bonnie R Joubert ${ }^{36}$, Stefan Karrasch ${ }^{49}$, Norman Klopp ${ }^{50}$, Beate Koch $^{51}$, Stephen B Kritchevsky ${ }^{52}$, Lenore J Launer ${ }^{34}$, Yongmei Liu ${ }^{53}$, Laura R Loehr ${ }^{33}$, Kurt Lohman ${ }^{54}$, Ruth J F Loos ${ }^{11}$, Thomas Lumley ${ }^{55}$, Khalid A Al Balushi ${ }^{7}$, Wei Q Ang ${ }^{56}$, R Graham Barr ${ }^{57}$, John Beilby ${ }^{58,59}$, John D Blakey ${ }^{7}$, Mladen Boban ${ }^{60}$, Vesna Boraska ${ }^{60}$, Jonas Brisman ${ }^{61}$, John R Britton ${ }^{62}$, Guy G Brusselle ${ }^{63}$, Cyrus Cooper ${ }^{64}$, Ivan Curjuric $^{65,66}$, Santosh Dahgam ${ }^{61}$, Ian J Deary ${ }^{24,25}$, Shah Ebrahim ${ }^{67,68}$, Mark Eijgelsheim ${ }^{3}$, Clyde Francks ${ }^{69}$, Darya Gaysina $^{70}$, Raquel Granell ${ }^{71}$, Xiangjun Gu ${ }^{20}$, John L Hankinson ${ }^{72}$, Rebecca Hardy ${ }^{70}$, Sarah E Harris ${ }^{24,73}$, John Henderson ${ }^{71}$, Amanda Henry ${ }^{7}$, Aroon D Hingorani ${ }^{74}$, Albert Hofman ${ }^{3,75}$, Patrick G Holt ${ }^{76}$, Jennie Hui ${ }^{48,59,77,78}$, Michael L Hunter ${ }^{48,78}$, Medea Imboden ${ }^{65,66}$, Karen A Jameson ${ }^{64}$, Shona M Kerr ${ }^{79}$, Ivana Kolcic ${ }^{60}$, Florian Kronenberg ${ }^{80}$, Jason Z Liu ${ }^{81}$, Jonathan Marchini ${ }^{81}$, Tricia McKeever ${ }^{62}$, Andrew D Morris ${ }^{82}$, Anna-Carin Olin ${ }^{61}$, David J Porteous ${ }^{79}$, Dirkje S Postma ${ }^{83}$, Stephen S Rich ${ }^{22}$, Susan M Ring ${ }^{71}$, Fernando Rivadeneira ${ }^{3,75,84}$, Thierry Rochat ${ }^{85}$, Avan Aihie Sayer ${ }^{64}$, Ian Sayers ${ }^{7}$, Peter D Sly ${ }^{76}$, George Davey Smith ${ }^{17}$, Akshay Sood ${ }^{86}$, John M Starr ${ }^{24,87}$, André G Uitterlinden ${ }^{3,75,84}$, Judith M Vonk $^{88}$, S Goya Wannamethe ${ }^{89}$, Peter H Whincup ${ }^{90}$, Cisca Wijmenga ${ }^{91}$, O Dale Williams ${ }^{92}$, Andrew Wong ${ }^{70}$, Massimo Mangino ${ }^{9}$, Kristin D Marciante ${ }^{6,41}$, Wendy L McArdle ${ }^{71}$, Bernd Meibohm ${ }^{93}$, Alanna C Morrison ${ }^{21}$, Kari E North ${ }^{33}$, Ernst Omenaas ${ }^{94}$, Lyle J Palmer ${ }^{18,19}$, Kirsi H Pietiläinen ${ }^{95-97}$, Isabelle Pin ${ }^{98-100}$, Ozren Polašek ${ }^{60,101}$, Anneli Pouta ${ }^{102}$, Bruce M Psaty ${ }^{6,41-43}$, Anna-Liisa Hartikainen ${ }^{103}$, Taina Rantanen ${ }^{104}$, Samuli Ripatti ${ }^{97,105}$, Jerome I Rotter ${ }^{106}$, Igor Rudan ${ }^{31,35,101}$, Alicja R Rudnicka ${ }^{90}$, Holger Schulz ${ }^{107}$, So-Youn Shin ${ }^{29}$, Tim D Spector ${ }^{9}$, Ida Surakka ${ }^{97,105}$, Veronique Vitart ${ }^{14}$, Henry Völzke ${ }^{108}$, Nicholas J Wareham ${ }^{11}$, Nicole M Warrington ${ }^{19,56}$, H-Erich Wichmann ${ }^{107,109,110}$, Sarah H Wild ${ }^{31}$, Jemma B Wilk ${ }^{111}$, Matthias Wjst ${ }^{12,113}$, Alan F Wright ${ }^{14}$, Lina Zgaga ${ }^{31,114}$, Tatijana Zemunik ${ }^{60}$, Craig E Pennell ${ }^{56}$, Fredrik Nyberg ${ }^{61,115}$, Diana Kuh ${ }^{70}$, John W Holloway ${ }^{116,117}$, H Marike Boezen ${ }^{88}$, Debbie A Lawlor ${ }^{17}$, Richard W Morris ${ }^{89}$, Nicole Probst-Hensch ${ }^{65,66}$, The International Lung Cancer Consortium ${ }^{127}$, GIANT consortium $^{127}$, Jaakko Kaprio ${ }^{44,96,97}$, James F Wilson ${ }^{31}$, Caroline Hayward ${ }^{14}$, Mika Kähönen ${ }^{118}$, Joachim Heinrich ${ }^{107}$, Arthur W Musk ${ }^{47,48,78,119}$, Deborah L Jarvis ${ }^{38,120}$, Sven Gläser ${ }^{121}$, Marjo-Riitta Järvelin 39,102,120,122,123, Bruno H Ch Stricker 3,4,75,84,124,128, Paul Elliott $39,120,128$, George T O'Connor ${ }^{125,126,128}$, David P Strachan ${ }^{90,128}$, Stephanie J London ${ }^{36,128}$, Ian P Hall ${ }^{7,128}$, Vilmundur Gudnason ${ }^{12,13,128} \&$ Martin D Tobin ${ }^{1,2,128}$

\footnotetext{
${ }^{1}$ Department of Health Sciences, University of Leicester, Leicester, UK. ${ }^{2}$ Department of Genetics, University of Leicester, Leicester, UK. ${ }^{3}$ Department of Epidemiology, Erasmus MC, Rotterdam, The Netherlands. ${ }^{4}$ Inspectorate of Healthcare, The Hague, The Netherlands. ${ }^{5}$ Center for Lung Biology, University of Washington, Seattle, Washington, USA. ${ }^{6}$ Department of Medicine, University of Washington, Seattle, Washington, USA. ${ }^{7}$ Division of Therapeutics and Molecular Medicine, Nottingham Respiratory Biomedical Research Unit, University Hospital of Nottingham, Nottingham, London, UK. ${ }^{8}$ Division of Nutritional Sciences, Cornell University Ithaca, New York, USA. ${ }^{9}$ Department of Twin Research and Genetic Epidemiology, King's College London, London, UK. ${ }^{10}$ Discipline of Genetics, Faculty of Medicine, Memorial University of Newfoundland, St. John's, Newfoundland, Canada. ${ }^{11}$ Medical Research Council (MRC) Epidemiology Unit, Institute of Metabolic Science, Addenbrooke's Hospital, Cambridge, UK. ${ }^{12}$ Icelandic Heart Association, Kopavogur, Iceland. ${ }^{13}$ University of Iceland, Reykjavik, Iceland. ${ }^{14}$ MRC Human Genetics Unit, Institute of Genetics and Molecular Medicine, Western General Hospital, Edinburgh, UK. ${ }^{15}$ Institute of Genetic Epidemiology, Helmholtz Zentrum München-German Research Center for Environmental Health, Neuherberg, Germany. ${ }^{16}$ School of Medicine, University of St. Andrews, St. Andrews, Scotland, UK. ${ }^{17}$ MRC Centre for Causal Analyses in Translational Epidemiology, School of Social and Community Medicine, University of Bristol, Bristol, UK. ${ }^{18}$ Genetic Epidemiology and Biostatistics Platform, Ontario Institute for Cancer Research, Toronto, Ontario, Canada. ${ }^{19}$ Prosserman Centre for Health Research, Samuel Lunenfeld Research Institute, Toronto, Ontario, Canada. ${ }^{20}$ Brown Foundation Institute of Molecular Medicine, University of Texas at Houston, Houston, Texas, USA. ${ }^{21}$ Human Genetics Center, School of Public Health, University of Texas at Houston, Houston, Texas, USA. ${ }^{22}$ Center for Public Health Genomics, University of Virginia, Charlottesville, Virginia, USA. ${ }^{23}$ Department of Public Health Sciences, Division of Biostatistics and Epidemiology, University of Virginia, Charlottesville, Virginia, USA. ${ }^{24}$ Centre for Cognitive Ageing and Cognitive Epidemiology, The University of Edinburgh, Edinburgh, UK. ${ }^{25}$ Department of Psychology, The University of Edinburgh, Edinburgh, UK. ${ }^{26}$ Clinical Pharmacology and the Genome Centre, William Harvey Research Institute, Barts and The London School of Medicine and Dentistry, Queen Mary University of London, London, UK. ${ }^{27}$ Department of Thoracic Surgery, Vanderbilt University, Nashville, Tennessee, USA. ${ }^{28}$ Division of Epidemiology, Vanderbilt University, Nashville, Tennessee, USA. ${ }^{29}$ Wellcome Trust Sanger Institute, Genome Campus, Hinxton, Cambridge, UK. ${ }^{30}$ University of Cambridge Metabolic Research Labs, Institute of Metabolic Science Addenbrooke's Hospital, Cambridge, UK. ${ }^{31}$ Centre for Population Health Sciences, The University of Edinburgh, Edinburgh, UK. ${ }^{32}$ Department of Biostatistics, Gillings School of Global Public Health, University of North Carolina, Chapel Hill, North Carolina, USA. ${ }^{33}$ Department of Epidemiology, Gillings School of Global Public Health, University of North Carolina, Chapel Hill, North Carolina, USA. ${ }^{34}$ Laboratory of Epidemiology, Demography, and Biometry, National Institute on Aging, National Institutes of Health, Bethesda, Maryland, USA. ${ }^{35}$ Croatian Centre for Global Health, The University of Split Medical School, Split, Croatia. ${ }^{36}$ Epidemiology
} 
Branch, National Institute of Environmental Health Sciences, National Institutes of Health, Department of Health and Human Services, Research Triangle Park, North Carolina, USA. ${ }^{37}$ Behavioral Health Epidemiology Program, Research Triangle Institute International, Research Triangle Park, North Carolina, USA. ${ }^{38}$ Respiratory Epidemiology and Public Health, Imperial College London, London, UK. ${ }^{39}$ Department of Epidemiology and Biostatistics, Imperial College London, London, UK. ${ }^{40}$ Department of Medical and Molecular Genetics, King's College London, Guy's Hospital, London, UK. ${ }^{41}$ Cardiovascular Health Research Unit, University of

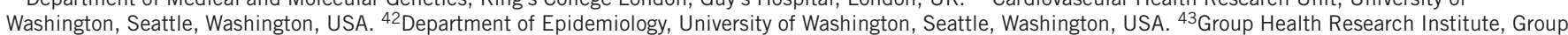
Health Cooperative, Seattle, Washington, USA. ${ }^{44}$ National Institute for Health and Welfare, Helsinki, Finland. ${ }^{45}$ Interfaculty Institute for Genetics and Functional Genomics, Department of Functional Genomics, University of Greifswald, Greifswald, Germany. ${ }^{46}$ Department of Pulmonary Physiology and Sleep Medicine/West Australian Sleep Disorders Research Institute, Sir Charles Gairdner Hospital, Nedlands, Western Australia, Australia. ${ }^{47}$ The School of Medicine and Pharmacology, University of Western Australia, Perth, Western Australia, Australia. ${ }^{48}$ Busselton Population Medical Research Foundation, Department of Respiratory Medicine, Sir Charles Gairdner Hospital, Nedlands, Western Australia, Australia. ${ }^{49}$ Institute and Outpatient Clinic for Occupational, Social and Environmental Medicine, LudwigMaximilians-University, Munich, Germany. ${ }^{50}$ Unit for Molecular Epidemiology, Helmholtz Zentrum München-German Research Center for Environmental Health, Neuherberg, Germany. ${ }^{51}$ Department of Internal Medicine B, University Hospital Greifswald, Greifswald, Germany. ${ }^{52}$ Sticht Center on Aging, Wake Forest School of Medicine, Winston-Salem, North Carolina, USA. ${ }^{53}$ Epidemiology, Wake Forest School of Medicine, Winston-Salem, North Carolina, USA. ${ }^{54}$ Department of Biostatistical Sciences, Division of Public Health Sciences, Wake Forest University School of Medicine, Winston-Salem, North Carolina, USA. ${ }^{55}$ Department of Statistics, University

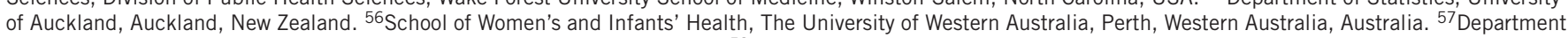
of Medicine, Columbia University Medical Center, New York, New York, USA. ${ }^{58}$ Department of Surgery and Pathology, University of Western Australia, Nedlands, Western Australia, Australia. ${ }^{59}$ PathWest Laboratory Medicine of Western Australia, Queen Elizabeth II Medical Centre, Nedlands, Western Australia, Australia. ${ }^{60}$ Faculty of Medicine, University of Split, Croatia, Split, Croatia. ${ }^{61}$ Occupational and Environmental Medicine, Department of Public Health and Community Medicine, Institute of Medicine, Sahlgrenska Academy, University of Gothenburg, Gothenburg, Sweden. ${ }^{62}$ Division of Epidemiology and Public Health, School of Community Health Sciences and Nottingham Respiratory Biomedical Research Unit, University of Nottingham, Nottingham, UK. 63 Department of Respiratory Medicine, Ghent University Hospital, Ghent, Belgium. ${ }^{64} \mathrm{MRC}$ Lifecourse Epidemiology Unit, University of Southampton, Southampton, UK. ${ }^{65}$ Chronic Disease Epidemiology, Swiss Tropical and Public Health (TPH) Institute, Basel, Switzerland. ${ }^{66}$ University of Basel, Switzerland. ${ }^{67}$ Non-Communicable Diseases Epidemiology Unit, Department of Epidemiology and Population Health, London School of Hygiene and Tropical Medicine, London, UK. ${ }^{88}$ South Asia Centre for Chronic Disease, New Delhi, India. ${ }^{69}$ Max Planck Institute for Psycholinguistics, Nijmegen, The Netherlands. ${ }^{70}$ MRC Unit for Lifelong Health and Ageing, London, UK. ${ }^{71}$ School of Social and Community Medicine, University of Bristol, Bristol, UK. ${ }^{2}$ Hankinson Consulting, Inc, Athens, Georgia, USA. ${ }^{73}$ Medical Genetics Section, The University of Edinburgh, Edinburgh, UK. ${ }^{74}$ Department of Epidemiology and Public Health, University College London, London, UK. ${ }^{75}$ Netherlands Genomics Initiative (NGI)sponsored Netherlands Consortium for Healthy Aging (NCHA), The Netherlands. ${ }^{76}$ Telethon Institute for Child Health Research and Centre for Child Health Research, The University of Western Australia, Perth, Western Australia, Australia. ${ }^{77}$ School of Pathology and Laboratory Medicine, The University of Western Australia, Nedlands, Western Australia, Australia. ${ }^{78}$ School of Population Health, University of Western Australia, Nedlands, Western Australia, Australia. ${ }^{79}$ Molecular Medicine Centre, Institute of Genetics and Molecular Medicine, University of Edinburgh, Edinburgh, UK. ${ }^{80}$ Division of Genetic Epidemiology, Department of Medical Genetics, Molecular and Clinical Pharmacology, Innsbruck Medical University, Innsbruck, Austria. ${ }^{81}$ Department of Statistics, University of Oxford, Oxford, UK. ${ }^{82}$ Medical Research Institute, The University of Dundee, Dundee, UK. ${ }^{83}$ Department of Pulmonology, University Medical Center Groningen, University of Groningen, Groningen, The Netherlands. ${ }^{84}$ Department of Internal Medicine, Erasmus MC, Rotterdam, The Netherlands. ${ }^{85}$ Division of Pulmonary Medicine, University Hospitals of Geneva, Geneva, Switzerland. ${ }^{86}$ Department of Medicine, University of New Mexico, Albuquerque, New Mexico, USA. ${ }^{87}$ Geriatric Medicine Unit, The University of Edinburgh, Edinburgh, UK. ${ }^{88}$ Department of Epidemiology, University Medical Center Groningen, University of Groningen, Groningen, The Netherlands. ${ }^{89}$ Department of Primary Care and Population Health, University College London, London, UK. ${ }^{90}$ Division of Population Health Sciences and Education, St. George's University of London, London, UK. ${ }^{91}$ Department of Genetics, University Medical Center Groningen, University of Groningen, Groningen, The Netherlands. ${ }^{92}$ Division of Preventive Medicine, University of Alabama at Birmingham, Birmingham, USA. ${ }^{3}$ College of Pharmacy, University of Tennessee Health Science Center, Memphis, Tennessee, USA. ${ }^{94}$ Centre for Clinical Research, Haukeland University Hospital, Bergen, Norway. ${ }^{95}$ Obesity Research Unit, Department of Medicine, Division of Internal Medicine, Helsinki University Central Hospital, Helsinki, Finland. ${ }^{96} \mathrm{Hjelt} \mathrm{Institute,} \mathrm{Department} \mathrm{of} \mathrm{Public} \mathrm{Health,} \mathrm{University} \mathrm{of} \mathrm{Helsinki,} \mathrm{Helsinki,} \mathrm{Finland.}{ }^{97}$ Institute for Molecular Medicine, University of Helsinki, Helsinki, Finland. ${ }^{8}$ Pédiatrie, Centre Hospitalier Universitaire (CHU), Grenoble, France. 99 Inserm U823, Centre de Recherche Albert Bonniot, Grenoble, France. ${ }^{100}$ Université Joseph Fourier, Grenoble, France. ${ }^{101}$ Gen-Info Ltd, Zagreb, Croatia. ${ }^{102}$ Department of Children, Young People and Families, National Institute for Health and Welfare, Oulu, Finland. ${ }^{103}$ Institute of Clinical Medicine, University of Oulu, Oulu, Finland. ${ }^{104}$ Gerontology Research Centre, Department of Health Sciences, University of Jyväskylä, Jyväskylä, Finland. ${ }^{105}$ Public Health Genomics Unit, Department Of Chronic Disease Prevention, The National Institute for Health and Welfare, Helsinki, Finland. ${ }^{106}$ Medical Genetics Institute, Cedars-Sinai Medical Center, Los Angeles, California, USA. ${ }^{107}$ Institute of Epidemiology I, Helmholtz Zentrum München-German Research Center for Environmental Health, Neuherberg, Germany. 108Institute for Community Medicine, Study of Health In Pomerania (SHIP)/Clinical Epidemiological Research, University of Greifswald, Greifswald, Germany. 109 Institute of Medical Informatics, Biometry and Epidemiology, Chair of Epidemiology, Ludwig-Maximilians-Universität, Munich, Germany. ${ }^{110}$ Klinikum Grosshadern, Munich, Germany. ${ }^{111}$ Division of Aging, Department of Medicine, Brigham and Women's Hospital and Harvard Medical School, Boston, Massachusetts, USA. 112Institute of Lung Biology and Disease, Comprehensive Pneumology Center, Helmholtz Zentrum München, Neuherberg, Germany. ${ }^{113}$ Institute for Medical Statistics and Epidemiology (IMSE), Technical University Munich, Munich, Germany. ${ }^{114}$ Andrija Stampar School of Public Health, Faculty of Medicine, University of Zagreb, Zagreb, Croatia. 115 AstraZeneca Research and Development, Mölndal, Sweden. ${ }^{116}$ Human Development and Health, Faculty of Medicine, University of Southampton, Southampton, UK. ${ }^{117}$ Infection, Inflammation and Immunity, Faculty of Medicine, University of Southampton, Southampton, UK. ${ }^{118}$ Department of Clinical Physiology, University of Tampere and Tampere University Hospital, Tampere, Finland. ${ }^{119}$ Department of Respiratory Medicine, Sir Charles Gairdner Hospital, Nedlands, Western Australia, Australia. ${ }^{120}$ MRC Health Protection Agency (HPA) Centre for Environment and Health, Imperial College London, London, UK. 121 University Hospital Greifswald, Department of Internal Medicine B, Greifswald, Germany. ${ }^{122}$ Institute of Health Sciences, University of Oulu, Oulu, Finland. ${ }^{123}$ Biocenter Oulu, University of Oulu, Oulu, Finland. ${ }^{124}$ Department of Medical Informatics, Erasmus Medical Center, Rotterdam, The Netherlands. ${ }^{125}$ Pulmonary Center, Boston University School of Medicine, Boston, Massachusetts, USA. ${ }^{126}$ The National Heart, Lung and Blood Institute's Framingham Heart Study, Framingham, Massachusetts, USA. ${ }^{127}$ A full list of members is provided in the Supplementary Note. ${ }^{128}$ These authors contributed equally to this work. Correspondence should be addressed to M.D.T. (mt47@leicester.ac.uk) or S.J.L. (Iondon2@niehs.nih.gov). 


\section{ONLINE METHODS}

Study design. The study consisted of two stages. Stage 1 was a meta-analysis conducted on directly genotyped and imputed SNPs from individuals of European ancestry in 23 studies with a total of 48,201 individuals. Supplementary Table 1a gives the details of these studies. Thirty-four SNPs selected according to the results in stage 1 were followed up in stage 2 . The ten leading SNPs were followed up in up to 46,411 individuals of European ancestry, and the remaining 24 SNPs were followed up in a subset of up to 21,674 individuals (Fig. 1).

Stage 1 samples. A total of 23 studies, 17 from the SpiroMeta consortium and 6 from the CHARGE consortium, formed stage 1: AGES, ARIC, B58C T1DGC, B58C WTCCC, BHS1, CHS, ECRHS, EPIC (obese cases and populationbased studies), the EUROSPAN studies (CROATIA-Korcula, ORCADES and CROATIA-Vis), FHS, FTC (incorporating the FinnTwin 16 and Finnish Twin Study on Aging), Health 2000, Health ABC, KORA F4, KORA S3, NFBC1966, RS-I, RS-II, SHIP and TwinsUK-I (see Supplementary Table 1 for the definitions of all abbreviations). Measurements of spirometry for each study are described in the Supplementary Note. The genotyping platforms and quality-control criteria implemented by each study are described in Supplementary Table $\mathbf{1 b}$.

Imputation. Imputation of non-genotyped SNPs was undertaken with $\mathrm{MACH}^{47}$, IMPUTE ${ }^{48}$ or BIMBAM ${ }^{49}$ with pre-imputation filters and parameters as shown in Supplementary Table 1b. SNPs were excluded if the imputation information, assessed using r2.hat (MACH), info (IMPUTE) or OEvar (BIMBAM), was <0.3. In total, 2,706,349 SNPs were analyzed.

Transformation of data and genotype-phenotype association analysis. Linear regression of age, age ${ }^{2}$, sex, height and ancestry principal components was undertaken on $\mathrm{FEV}_{1}$ (milliliters) and $\mathrm{FEV}_{1} / \mathrm{FVC}$ (percent). The residuals were transformed to ranks and then transformed to normally distributed $z$-scores. These transformed residuals were then used as the phenotype for association testing under an additive genetic model, separately for ever smokers and never smokers. The software used is specified in Supplementary Table $\mathbf{1 b}$. Appropriate tests for association in related individuals were applied where necessary, as described in the Supplementary Note.

Meta-analysis of stage 1 data. All stage 1 study effect estimates, both for ever smokers and never smokers, were corrected using genomic control ${ }^{50}$ and were oriented to the forward strand of the NCBI build 36 reference sequence of the human genome, consistently using the alphabetically higher allele as the coded allele. Study-specific $\lambda$ estimates are shown in Supplementary Table 1. For each study, effect estimates and standard errors for ever smokers and never smokers were meta-analyzed using inverse-variance weighting. Genomic control was applied again to the pooled effect-size estimates for each study. Finally, effect-size estimates and standard errors were combined across studies using an inverse-variance-weighting meta-analysis, and genomic control was applied to the pooled effect-size estimates. To describe the effect of imperfect imputation on power, for each SNP we report the effective sample size ( $N$ effective), which is the sum of the study-specific products of the sample size and the imputation quality metric. Meta-analysis statistics and figures were produced using R version 2.9.2 (see URLs).

Selection of SNPs for stage 2. All regions selected for follow up in stage 2 contained a lead SNP with new evidence of association (all with $P<3 \times 10^{-6}$ ) with $\mathrm{FEV}_{1}$ and/or $\mathrm{FEV}_{1} / \mathrm{FVC}$, an $N$ effective $\geq 70 \%$ of the total stage 1 sample size and association signals from the surrounding SNPs that were consistent with their correlation (LD) with the leading SNP. Twenty-nine independent regions with a leading SNP meeting these criteria were assessed in stage 2 . Regions were defined as independent if the leading SNP from one region was $>500 \mathrm{~kb}$ from the leading SNP of any other region. Long-range LD was also investigated between leading SNPs of regions in or near the MHC on chromosome 6 (Supplementary Note). For two regions, the leading SNP had an $N$ effective $\geq 70 \%$ but $<80 \%$ of the stage 1 sample size and, therefore, a proxy SNP from each region $\left(r^{2}=1\right.$ and $\left.r^{2}=0.97\right)$ was also taken forward. For three regions, there were different leading SNPs for $\mathrm{FEV}_{1}$ and $\mathrm{FEV}_{1} / \mathrm{FVC}$, and so both leading SNPs were assessed. A total of 34 SNPs were analyzed in stage 2 and are listed in Supplementary Table 5b. Previously reported regions ${ }^{8-11,51,52}$ were not followed up. We present in Supplementary Table 5a association test statistics in stage 1 only for relevant SNPs from previously reported regions.

Stage 2 samples. The 34 SNPs were followed up in up to 11,275 individuals from seven studies with in silico data: CARDIA, CROATIA-Split, LifeLines, LBC1936, MESA-Lung, RS-III and TwinsUK-II (Supplementary Table 1). rs2647044 was not available from TwinsUK-II.

The 34 SNPs were ranked by $P$ value (for association with either FEV 1 or $\mathrm{FEV}_{1} / \mathrm{FVC}$ ), and the top ten leading SNPs were selected for follow up by genotyping in up to 35,136 individuals from ADONIX, BHS2, BRHS, BWHHS, Gedling, GS: SFHS, HCS, Nottingham Smokers, NSHD and SAPALDIA (Supplementary Table 1). If a SNP in the top ten had an $N$ effective $<80 \%$, only the proxy SNP was included in the top ten for follow up. For regions that showed association with both $\mathrm{FEV}_{1}$ and $\mathrm{FEV}_{1} / \mathrm{FVC}$, only the leading SNP with the lowest $P$ value for either trait was included if it was within the top ten SNPs. The study design is illustrated in Figure 1.

Meta-analysis of stage 2 data. All stage 2 studies provided effect estimates for ever smokers and never smokers, apart from Nottingham Smokers, as that study only included smokers. Studies with family data (BHS2 and GS: SFHS) analyzed ever smokers and never smokers together to account for the family correlation, adding the smoking status as a covariate in the model, and therefore provided smoking-adjusted effect estimates. All stage 2 study effect estimates were oriented to the forward strand of the NCBI build 36 reference sequence of the human genome, consistently using the alphabetically higher allele as the coded allele. For each study with separate results for ever smokers and never smokers, effect estimates and standard errors for ever smokers and never smokers were meta-analyzed using inverse-variance weighting. Genomic control was applied to the pooled effect sizes of those studies with in silico data that undertook the analysis genome wide. Effect estimates and standard errors were combined across the stage 2 studies using an inversevariance-weighting meta-analysis.

Combined analysis of stage 1 and stage 2 samples. A meta-analysis of stage 1 and 2 results was undertaken using inverse-variance weighting. We described associations as genome-wide significant if they had $P<5 \times 10^{-8}$.

PCR expression profiling. The mRNA expression profiles of TGFB2, MFAP2, HDAC4, EVI1, RARB, SPATA9, ARMC2, NCR3, CDC123, LRP1, CCDC38, SNRPF, MMP15, CFDP1, ZKSCAN3, KCNE2 and C10orf11 were determined in human lung tissue and primary cell samples using RT-PCR, including RNA from lung (Ambion/ABI), brain, airway smooth muscle cells and human bronchial epithelial cells (Clonetics42). Primer sequences are listed in Supplementary Table 2. Full details are provided in the Supplementary Note.

Lung function associations in our data of SNPs previously associated with lung function. In order to permit comparison of findings with recent studies of relevance to the field, we present association test statistics (in stage 1 only) for relevant SNPs from previously reported regions (Supplementary Table 5a). We included the regions (i) reported as showing genome-wide significant association $\left(P<5 \times 10^{-8}\right)$ with lung function, (ii) reported as showing genomewide significant association with COPD, providing that there was additional evidence of association with lung function and (iii) DAAM2, which reached borderline significance in the SpiroMeta consortium ${ }^{9}$. Within each of these regions, if multiple SNPs had been reported, we included all relevant SNPs and also the SNP that showed the strongest association in our data.

Association to other traits of lung-function-associated SNPs. Regions associated $\left(P<5 \times 10^{-8}\right)$ with lung function or COPD (and also associated with lung function) were looked up for other traits. Where multiple SNPs were reported for different traits or by different investigators, we aimed to include all relevant SNPs, except those having $r^{2}>0.9$ with another SNP in the region. We also included the SNPs that showed the strongest association in our data for each region. The following related traits were assessed: (i) lung function in 
children (Supplementary Table 3a); (ii) smoking amount and ever smoking versus never smoking in the Ox-GSK consortium ${ }^{25}$ dataset (Supplementary Table 3b); (iii) height in the GIANT consortium ${ }^{14}$ dataset (Supplementary Table 3c,e); and (iv) lung cancer in the International Lung Cancer Consortium (ILCCO) GWAS meta-analysis ${ }^{26}$ (Supplementary Table 3d).

Estimation of the number of undiscovered variants and calculation of the proportion of variance explained. We used the approach previously proposed $^{34}$ to estimate the number of independent variants associated with lung function measures that have similar effect sizes to the variants already reported and to calculate the proportion of the variance explained by them. We excluded discovery data when estimating effect sizes to avoid winner's curse bias and obtained the number of undiscovered variants using the discovery power to detect the unbiased effect sizes (Supplementary Table 6 and Supplementary Note).

Additional analyses. The top SNPs from our new loci and their proxies were searched for correlation with known common copy number variants and expression SNPs. Analyses to identify common pathways underlying the association signals for lung function were undertaken using MAGENTA v2 (ref. 53) and GRAIL $^{54}$. Full methods and results are given in the Supplementary Note.

47. Li, Y. \& Abecasis, G.R. Mach 1.0: rapid haplotype construction and missing genotype inference. Am. J. Hum. Genet. S79, 2290 (2006).

48. Marchini, J., Howie, B., Myers, S., McVean, G. \& Donnelly, P. A new multipoint method for genome-wide association studies by imputation of genotypes. Nat. Genet. 39 906-913 (2007)

49. Servin, B. \& Stephens, M. Imputation-based analysis of association studies: candidate regions and quantitative traits. PLoS Genet. 3, e114 (2007).

50. Devlin, B. \& Roeder, K. Genomic control for association studies. Biometrics $\mathbf{5 5}$, 997-1004 (1999).

51. Cho, M.H. et al. Variants in FAM13A are associated with chronic obstructive pulmonary disease. Nat. Genet. 42, 200-202 (2010).

52. Pillai, S.G. et al. Loci identified by genome-wide association studies influence different disease-related phenotypes in chronic obstructive pulmonary disease. Am. J. Respir. Crit. Care Med. 182, 1498-1505 (2010).

53. Segrè, A.V., Groop, L., Mootha, V.K., Daly, M.J. \& Altshuler, D. Common inherited variation in mitochondrial genes is not enriched for associations with type 2 diabetes or related glycemic traits. PLoS Genet. 6, e1001058 (2010).

54. Raychaudhuri, S. et al. Identifying relationships among genomic disease regions: predicting genes at pathogenic SNP associations and rare deletions. PLoS Genet. $\mathbf{5}$, e1000534 (2009). 